\title{
Ordinary Apocalypse: Zombies, Feminism and the Unmaking of Self
}

\author{
by \\ Tammy Mast
}

A thesis submitted to the Faculty of Graduate and Postdoctoral Affairs in partial fulfillment of the requirements for the degree of

\author{
Master of Arts \\ in \\ Master of Arts in Sociology \\ Carleton University \\ Ottawa, Ontario \\ (C) 2017, Tammy Mast
}




\begin{abstract}
This thesis is a reflexive examination of my own experience, as understood through my consumption of popular culture, specifically the television series and graphic novel, The Walking Dead. This project investigates the rich and complex sociocultural phenomenon of the self through an examination of my own self, as reflected and refracted through popular culture. The thesis is grounded in a feminist and cultural studies theoretical framework that examines the nature of knowledge and the production of meaning in our culture. The methodology for this project hybridizes two distinct ethnographic approaches: autoethnography and webnography. Specifically, I draw on the story arc of Lori and Andrea to demonstrate some of the ways that the post-apocalyptic world of the Walking Dead relies on a logic of masculinist protection to discursively and symbolically create a subordinate feminine identity, self or role for Lori and Andrea. I use my own emotional engagement with the series to expand the idea of apocalypse to more ordinary or quotidian aspects of our lives.
\end{abstract}




\section{Acknowledgements}

Thank you to my supervisor Dr. Kennelly. Your patience with my nonsense was endless!

Thank you to members of the faculty and staff in the Department of Sociology and

Anthropology who supported and advocated for me through this process.

Thank you to Dr. Taylor you have helped to keep me functioning.

Thank you to James even when we stumble we do it together.

Finally, this is work is dedicated to the three most important zombies in my life:

The first one.

The only one.

The last one. 


\section{Table of Contents}

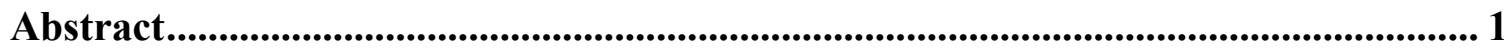

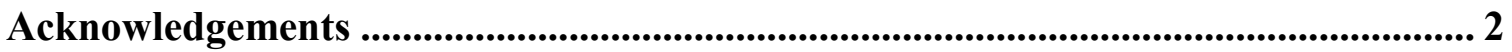

Table of Contents ......................................................................................................................... 3

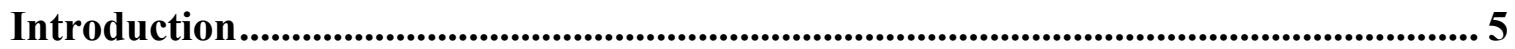

1.1 Knowledge, Reality, Self and That Which Lacks Self ........................................... 8

1.2 Becoming the Zombie Autoethnographer ............................................................

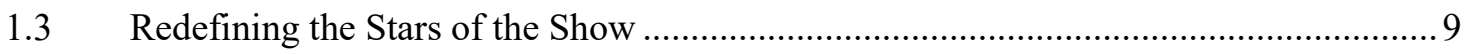

1.4 You Know You Left the Fat Chick in Charge of the Food, Right? ............................. 10

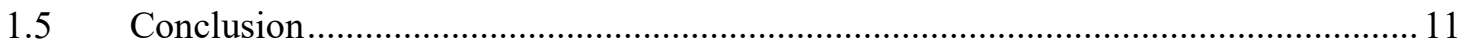

2 Chapter: Knowledge, Reality, Self and That Which Lacks Self............................ 12

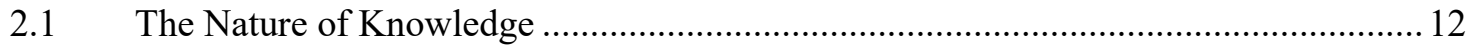

2.2 Theory of Duality: Fantasy/Reality Object/Subject Living/Dead .............................. 18

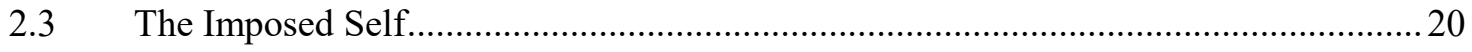

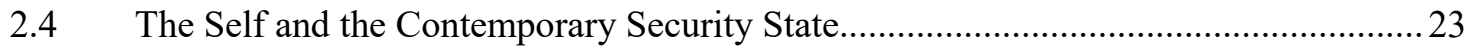

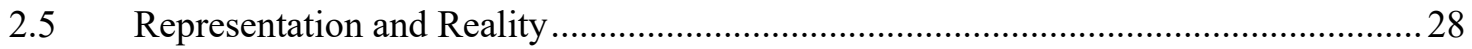

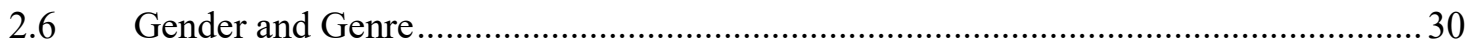

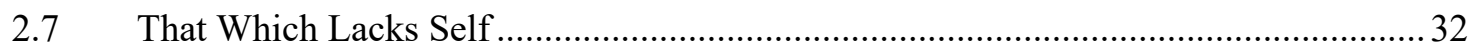

2.8 Denaturalizing \& Destabilizing the Object/Subject Binary ....................................... 35

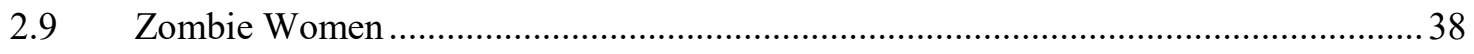

3 Chapter: Becoming the Zombie Autoethnographer ............................................. 41

3.1 Being the Autoethnographic Webnographer ........................................................ 41

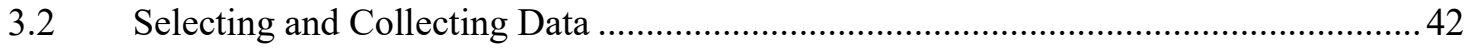


4 Chapter: Ordinary Apocalypse: A Story about Women...................................... 54

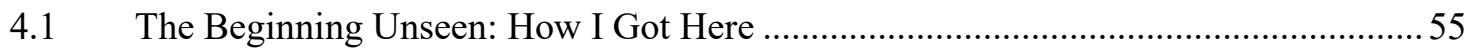

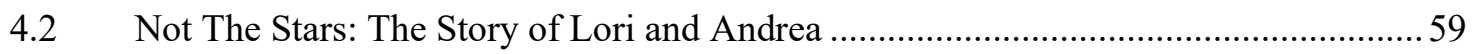

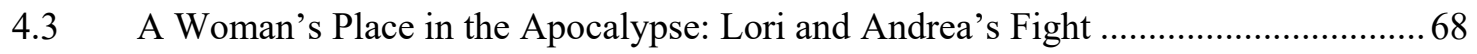

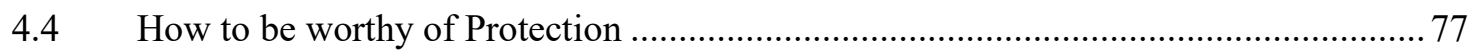

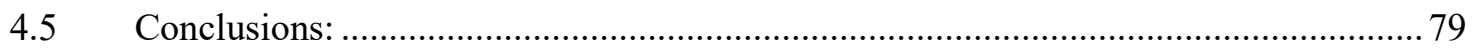

5 Chapter: You Know You Left the Fat Chick in Charge of the Food Right? ...... 81

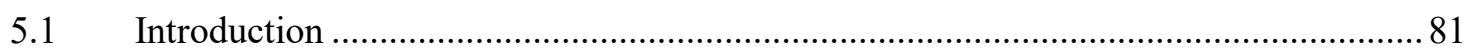

5.2 Matters of Representation: What is the Symbolic Meaning of a Woman .................... 82

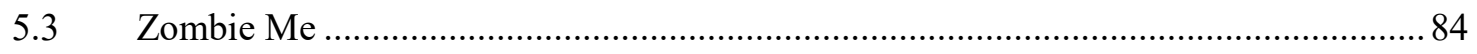

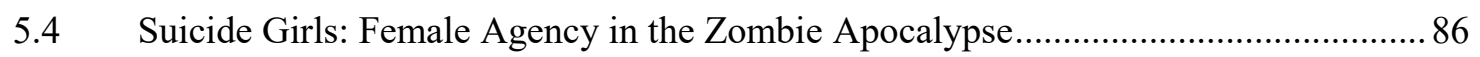

5.5 Violence and Sexuality Unscene: Michonne Sanitized ........................................... 90

5.6 Olivia: You Know You Left the Fat Chick in Charge of the Food Right?.................. 94

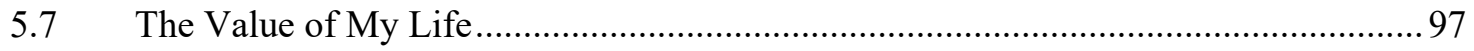

6 Chapter: Conclusion .................................................................................................. 99

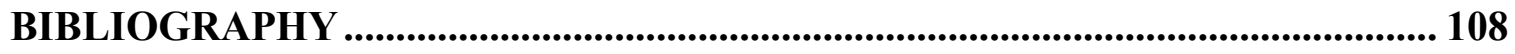




\section{Introduction}

There is a way that we think things will go for us in life. In all our endeavours we begin with an idea of what we think and expect the path forward to be. Any objective that we pursue in our lives, before it has even been completed has important meaning because of the way that we expect and plan for it to figure in the overall plan we have for life. The endeavours that we undertake, be they in the form of educational goals, career goals, or personal goals, become a locus for the production of meaning in our life. The meaning is not only something internal to an endeavour; meaning is located in the expectations, hopes, and aspirations that we connect to the endeavour. Furthermore, it is the reflexive relationship between the individual and the path to the achievement of a goal that creates all meaning related to that goal. The reality of life is that things do not always go as planned or expected. The disruptions, uncertainties, and instabilities in the path to the completion of any project create additional meaning in that endeavour itself.

The methodology for the current project was developed around the significantly disrupted path that one particular life (my own) took in the achievement of an academic goal. In addition to structuring the methodology for the current project, some of my own personal experiences of instability and uncertainty form the narrative frame upon which this project is built. As I will discuss in subsequent chapters of this project, some of the instability, uncertainty, and disruption is linked to my own struggles with mental illness. I have come to recognize the ways that instability, uncertainty, and disruption have drastically impacted my understanding of my life and the development of this project. There are important ways that these personal struggles have directly influenced the development of the methodology for this project. As a means of achieving this 
academic goal I have chosen to investigate the rich and complex sociocultural phenomenon of the self. As sociology is the investigation of culture I am interested specifically in the relationship between the self and some aspect of the culture at large. Of particular interest for me is the relationship between popular culture and the way that we understand and construct our sense of self. As a methodological approach, I have chosen to explore the issue of the self and its relationship to popular culture through a consideration of my own self. I am investigating the notion of self by exploring myself. Furthermore, this project and the development of this methodology is an explicit effort to mobilize what I believe is my own valuable and unique perspective on the self. It is the goal of this project to investigate, by means of my own project of self-understanding, the relationship between the cultural and social construction of the self and popular culture. Specifically, I focus on one particular popular cultural text that I am a fan of, the popular television series The Walking Dead (Kirkman, 2010-Present).

This project is a reflexive examination of my own experience; as such I would like to orient the reader to how my experiences as a student led me to my research interest in popular culture. During my undergraduate education, I developed a research interest in celebrity and media. I have written and spoken about the analysis of the symbolic nature and function of celebrity. My work with celebrity led me to better understand the ways that our culture adapts to social change. Scholars have conceptualized celebrity and popular culture more generally as a replacement for the icons and social structures that have faded from our contemporary social lives (Turner, 2004), (Alexander, 2010). I have conducted analyses of representations of race in the news media. I have conducted analyses of the television series Mad Men as well as 
analyses of various reality television programs. In all of these analyses I am considering the fundamental and basic meanings that are reproduced or recreated in each of the cultural texts, practices, or symbols that I explored. Clifford Geertz's (1973) idea that culture is "the stories we tell ourselves about ourselves" illustrates the importance of serious academic examination of popular culture. Popular culture is precisely the stories we tell ourselves. It is vitally important to remember that the popular cultural texts exist and are created in a larger cultural context, a context that is ever growing and ever changing. Because cultures at large are ever growing and ever changing, the meaning that a popular cultural text carries will change along with the culture. Furthermore, the meaning of any given cultural text varies from person to person and can even mean different things to the same person at different times. Jensen argues that the cultural text and the audience that consumes that text are "complimentary elements of one area of inquiry which thus addresses both the discursive and the social aspects of communication (Jensen, 1991, p. 135). Furthermore, Jensen asserts that 'there can be no 'effect' without 'meaning" (ibid). Jensen explains that popular culture and mass communication are a set of "cultural practices producing and circulating meaning in social context" (Jensen, 1991, p. 135). Because of popular culture and media's role in producing and circulating meaning, the consideration of popular culture can elucidate the way that fundamental forms of social inequality are maintained and reproduced. One of the goals of this project is to illustrate and understand how the personal and individual meanings, constructions and understandings that we as social agents generate about ourselves, our lives and our world are all a part of a broader system of cultural meaning making. Academic research 
that explores popular culture is vitally important for understanding the fundamental values and ethics at the center of our culture.

\subsection{Knowledge, Reality, Self and That Which Lacks Self}

I will begin this project with a conceptual and theoretical discussion of the nature of knowledge. I will unpack some of the ways that our culture privileges some kinds of knowledge over others. I will demonstrate how this privileging of particular kinds of knowledge leads to a culture of superiority in the dialogue and relationship between qualitative social sciences and other more seemingly objective quantitative sources of knowledge. Furthermore, I will demonstrate how this hierarchy of knowledge is fundamentally a broader symptom of a more general cultural imbalance of power. I will examine phronetic knowledge as tool to undermine the culture of superiority that has so deeply infected the academic cultural understanding of knowledge.

At this point I will shift gears: I will focus on the development of the theoretical foundations for this project. This section will explain the development of the theoretical foundation for a project concerned with popular culture, zombies, fantasy, gender, emotion, and the self. This chapter will outline a set of theoretical perspectives demonstrating the production of meaning in our culture. Furthermore, the self and identity will also be theoretically positioned as expressions of collective cultural production of meaning. Finally, the theory chapter will introduce the cultural symbol of the zombie. 


\subsection{Becoming the Zombie Autoethnographer}

This chapter will introduce two methods of ethnographic enquiry: webnography and autoethnography. I will address the specific hows and whys of my data collection process. Importantly this chapter will demonstrate how I mobilized and hybridized the two distinct ethnographic approaches. This chapter will demonstrate how the reflexive process of hybridization facilitated the identification of not only the relevant data but also appropriate deployment of the research methodology for the project. Furthermore, this chapter will demonstrate how the process of hybridization is ongoing throughout the execution of the project. I will explain that the mechanisms of interrelationship between the two methodologies is in a fundamental way one of the products or results of this project. I will conclude this chapter with a discussion of the role of the writing process in this methodology.

\subsection{Redefining the Stars of the Show}

The story of The Walking Dead (TWD) series is primarily centered on the male characters Rick and Carl Grimes. However, with this chapter I reframe the story of the first three seasons of TWD as a story primarily about two women, Lori and Andrea. The story arc of Lori and Andrea will outline some of the ways that the post-apocalyptic world of TWD relies on a logic of masculinist protection to discursively and symbolically create a subordinate feminine identity, self, or role for Lori and Andrea. I will consider the way that these two characters either accept or reject the identities or roles available to them in the world of TWD. Finally, I will discuss how the post-apocalyptic feminine self created for the characters Lori and Andrea in the world of TWD limits these female characters to roles that support and serve to facilitate the character development of the 
male characters in the series. The story told about the characters Lori and Andrea will also be a telling of parts of my own story. With this chapter I will explore the way that my emotional and academic engagement with this series has facilitated a richer understanding of my own life and self. I believe that my own experiences of disruption are a significant part of what makes the storytelling of TWD so compelling to me. My careful emotional and academic consideration of the series TWD has led to increased understanding of many of the events in my own life. Furthermore, consideration of my own life will serve as an exploration of the nature of the phenomenon of apocalypse. I will explore significant ruptures in my own life in order to consider the question: what is an apocalypse? I will use my own emotional engagement with the series to expand the idea of apocalypse to more ordinary or quotidian aspects of our lives.

\subsection{You Know You Left the Fat Chick in Charge of the Food, Right?}

This chapter will contain a more in-depth analysis of some of the discursive and symbolic ways that the story of the TWD constructs its female characters. It will demonstrate how the symbolic meaning of the female characters and their story arcs is infected with the logic of masculinist protection, with its restrictive and mutually exclusive gender roles. I will consider the way that TWD symbolically constructs women as boundary figures between life and death. I will demonstrate how the women of TWD are symbolically constructed in ways reminiscent of the very monsters that haunt their world, zombies. I will demonstrate how this zombie status is manifested both physically and discursively for the female characters of the series. I will consider an online fan conversation about a very minor character named Olivia and some of the ways that I found this conversation about this character to be reflected in some of my own 
experiences. I will then consider some of the ways that I have applied this discursive and symbolic zombie status to my understanding of my sense of self.

\subsection{Conclusion}

I will conclude this thesis by discussing some of the implications of the analysis that I have developed with this project. I will consider the ways that my experience of disruption, instability, and uncertainty have influenced both the analysis contained in this project as well as my understanding of, and ability to become, myself. Finally, I will conclude that in both, the contemporary world and in the world of TWD, women are faced with a requirement to live up to the standard of the 'good woman' or risk being reduced to a zombie status where their lives are have no value. 


\section{Knowledge, Reality, Self, and That Which Lacks Self}

\section{Chapter: The Nature of Knowledge}

Before examining some specific methodological approaches, I think it is appropriate to include a theoretical discussion of the nature of knowledge in order to examine how methodology is connected to the production of knowledge. Knowledge is in many ways the defining feature of the human species: we collect, create, share, and build knowledge. But what is the definition of knowledge? Natural sciences such as physics or biology make very particular claims about what is known with the knowledge they produce. Natural sciences make claims that they allow access to the objective, true reality of the universe. In 1996, physicist Alan Sokal submitted an article to an academic journal dedicated to cultural studies. The article claimed to be a discussion of the social construction of a complex physics theory. However, after the journal published the article Sokal announced it as a hoax (Flyvbjerg, 2011). The resulting discussion focused on the failing of the journal that published the article rather than on the fraudulent submission from Sokal. Sokal's action was viewed as a demonstration of both his and his discipline's intellectual superiority over the review board of this journal. I think that the Sokal hoax demonstrates how this claim to objectivity forms the basis of the culture of superiority that structures the relationship between the natural and social sciences.

Claims to access objective truth are problematic regardless of whether those claims exist in the natural sciences or the social sciences. Roulston, deMarrais and Lewis (2003), Denzin (2001), Charmaz (2006) and Hawkesworth (2006) argue that historical scientific claims to objectivity have always been conducted in a culture and language that 
fundamentally privileges the male over the female. Hawkesworth (2006), argues that in western language and culture the female is seen as the incomplete or defective male. The male is privileged by virtue of his completeness and able to occupy both the male and the neutral or objective subject position. Butler (1999) also explores the different value and understanding attributed to the male and female in our culture. Butler argues that femininity is understood as fundamentally 'embodied' while the masculine is located in the 'disembodied' mind. Importantly, Butler points out that to question the embodied/feminine, disembodied/masculine division it is first necessary to question the fundamental proposition of the body/mind duality.

One of the ways that Butler demonstrates this is in her discussion of the sex/gender binary. Butler (1999) argues against the common conceptualization of sex as only that which is biological and gender as the social construct of masculine and feminine. Butler makes it clear that gender and sex are mutually informing terms, both of which are intimately connected to the social context within which the social subject exists. The link to the body/mind duality is seen in the typical configuration of sex as something biological and gender as something discursively produced. Butler (2004) argues that the distinction between the material body and language is artificial because the body is defined and understood through language. Realizing that our understanding is eternally achieved and enacted through our linguistic representation of the world and ourselves we can begin to see how any attempts to claim or conduct objective research 
will inherently be incomplete. It is through our linguistic representation of the social world that we come to understand it and gain meaning from it.

Just as the body is fundamentally understood through the framework of language so too is our research. There is no objective path to knowledge that a human can follow because every path to knowledge, even those structured by the scientific method, are influenced and directed by the individual human walking the path. Furthermore, efforts to control variables and obtain objective results can in reality skew results. The United States National Institute of Health (NIH) had to direct pharmaceutical research companies to begin including female animal subjects in their drug trials, which had previously only been focused on male animal subjects in an effort to control as many variables as possible, producing scientifically objective, reproducible and valid results (Rabin, 2014). Importantly the NIH has evidence that women experience more severe drug reactions than men (Rabin, 2014). In this case the natural sciences' quest for objective validity produced insufficient knowledge that had harmful results for women who experienced unexpected negative consequences from pharmaceuticals. Furthermore, there is a social context within which knowledge is produced. The knowledge that a culture produces is not immune from the influence of the bias and prejudices of that culture. In the case of the NIH's need to direct pharmaceutical companies to include female research subjects, the view of the male body as a neutral state perpetuated the idea that pharmaceutical research using only male subjects would produce a more objective, neutral or valid result.

It is necessary that a consideration of the assumptions and assertions underlying the fundamental understanding of the nature of knowledge be at the heart of any 
discussion of methodology. According to Foucault (1978) power and knowledge are intimately connected. Foucault (1978) asserts that knowledge is used to justify and create power, that power is implicit in the production of knowledge, and that the two concepts mutually coexist. Because power and knowledge are so intimately connected, the nature of knowledge must always be critically examined to account for power in its creation. In our contemporary culture, particular kinds of knowledge are valued more than other types of knowledge. The differential value that is given to different kinds of knowledge is demonstrative of the interrelation of power and knowledge. The attribution of value to knowledge confers power and authority on that knowledge.

Flyvbjerg (2011) explores the way that types of knowledge are valued by asking why it is appropriate for the so called natural sciences to be critical of social sciences while the reverse critiques by social science of the natural sciences are not accepted. As Flyvbjerg explains, this is the product of a differential value that is attributed to forms of knowledge and ways of knowing. Flyvbjerg draws on Aristotle and conceptualizes knowledge as comprising three types: Episteme, Techne and Phronesis. Flyvbjerg explains Episteme as scientific knowledge, that is universal, invariable and contextindependent. Techne refers to practical context-dependent knowledge oriented towards production. Both Episteme (epistemology) and Techne (technique or technology) have contemporary linguistic equivalents that reflect the general meaning of these ancient ideas as used by Aristotle. However, the third aspect of knowledge as outlined by Flyvbjerg, phronesis, has no contemporary equivalent.

The lack of a clear connection between phronesis and contemporary understandings of knowledge is linked to a shift in the dominant understanding of the 
primary function or role of knowledge in culture. Flyvbjerg (2011), argues that as the enlightenment and then modernity progressed there was an increase in the dominance of instrumental rationality as the motivator for the production of knowledge; or phrased as a question: what can knowledge do for society? According to Flyvbjerg the emphasis on what knowledge can do for society has been at the expense of forms of knowledge that reflexively analyze the goals and values that are a precondition for the "enlightened development" of society (2011, p. 53). The pursuit of knowledge that can do something for society has been at the expense of critical examination of why society is as it is. Flyvbjerg asserts that phronetic knowledge is not weak or lacking because it lacks some aspects that other forms of knowledge value. Rather, phronetic knowledge has strength in the ability to assess aspects of our world that other forms of knowledge have no means to examine. In this way criticism by the natural sciences of the social sciences is an "apples and oranges" comparison. The kinds of knowledge that are produced by phronetic social science are fundamentally different from knowledge types produced by the natural sciences. It is only the way that our culture has structured the value of knowledge that leads to an illusion of the superiority of the natural sciences over the social sciences as a means to recognize and understand reality.

In an effort to produce phronetic social science, I make no claim to be able to access objective knowledge or truth. Any and all knowledge that I understand or produce is fundamentally and irrevocably tied to the context that is me as an individual doing research. However, I do not see this as a weakness because an examination of my role as a producer of knowledge offers its own kind of knowledge. Considering and reporting variables that have led to a particular path of knowledge production can provide 
information about the culture that helped forge that path. By placing a priority on the particular, phronetic social science produces knowledge about culture (Flyvbjerg, 2011). This approach is an acknowledgement of a distinct individual context, which is to say the context of the person who works to produce knowledge, and any claims to objectivity are fundamentally shaped by the individual and specific nature of each researcher's context.

At this point I would like to summarize: Though the foundation and sources of knowledge are varied, our culture has privileged particular kinds of knowledge as more valid and important than others. This privilege is rooted in a fundamental cultural shift which emphasizes the production of knowledge that performs a function or does something for society. The emphasis on what knowledge can do for society has been at the expense of knowledge that examines what is good for society (Flyvbjerg, 2011). The differential value that our culture places on different kinds of knowledge has had a direct impact on my experience as a researcher. In a course I took for my M.A. which explored the logic of the research process, I was reminded again and again that when I am finished this project I will need to answer a very fundamental question about my project: ‘so what?' This question is itself a reflection of the privilege that is given to instrumental knowledge in our culture. When I complete and defend this project I will be responsible for explaining and justifying why my work is important; why it matters. I can understand how a project rooted in activist activity has a clear answer to this question; there is a clear goal to be achieved. As my own research was not focused on activism, nor on the 
sciences, I experienced less certainty that my research would 'matter' when I initially set out.

As will become more apparent later in this thesis, disruption, destabilization, uncertainty, and transgression are central components of the theoretical understandings developed over the course of this project. However, it is important that the role of uncertainty, destabilization, and transgression be acknowledged in the development of the methodology herein as well. The methodology used for this project was on more than one occasion interrupted by life-altering, destabilizing events. Because destabilizing events had a unique impact on my research path, I think it is important that this instability be reflected in the presentation of the methodology for this project. At one point in the development of this methodology I experienced a catastrophically disruptive mental health crisis. This mental health crisis interfered with my ability to perform as a student and to function in the social world. My project and my goal of completing the course work necessary for the graduate program that this project is the culmination of were both halted for an extended period of time. For that reason I will now shift away from some of the conceptual methodological issues at the center of this project and explore the way that the theoretical understanding of uncertainty, destabilization. and transgression have been at the heart of this project.

\subsection{Theory of Duality: Fantasy/Reality Object/Subject Living/Dead}

In crafting this theoretical foundation, I was faced with the challenge of integrating theoretical understandings of a variety of seemingly unconnected variables. How do I build a theoretical foundation for a project concerned with popular culture, 
zombies, fantasy, gender, race, emotion, and the self? Initially I struggled to make sense of the theoretical framework when it was disentangled from the analysis. The connections between the theoretical perspectives got lost in the act of making them distinct from the analysis. The theory stopped making sense to me. The solution took the form of something of a regression. To make sense of the theory again it was necessary to bring it back together with the analysis. It was only in considering the analysis and theory together that I was able to understand how to construct the theoretical framework for the entire project.

In an early draft of a proposal for this project I became immersed in the big ideas that were at the center of the project. I wrote a piece that essentially outlined my project as one that explores the very meaning of life itself through the lens of popular culture. A project addressing the meaning of life is of course beyond the scope of a single project. I mention this now because a turn back to this idea of meaning was necessary for me to build the theoretical framework. In considering the various theoretical frames I am using, I was able to identify just what the role of meaning is for this project. This section will outline a set of theoretical perspectives that demonstrate the nature of meaning in our culture. I will lay a foundation to demonstrate how even the seemingly internal preexisting states such as self and identity are actually a result of the collective cultural production of meaning. Furthermore, I will develop a theoretical frame that demonstrates how meanings are linguistically produced, embodied, and performed by our culture rather than meaning as a pre-existing condition. Finally, this section will introduce the phantasm that is at the center of this project: the zombie. The cultural symbol of the zombie will be 
introduced as a site for the critical consideration of a variety of aspects of our contemporary culture.

\subsection{The Imposed Self}

As a starting point for this theoretical discussion I would like to start with a very basic sociological concept. I do this not to be pedantic but because it allows me to build the complexity of my discussion as it progresses. Often, I find it is in consideration of some of the basic ideas that the fundamental ontological positions of this project can be identified. The human animal is not a species born with the resources and skills that it needs to make its way through life. The skills, knowledge, and abilities necessary for a human animal to be successful in any environment must be learned over time from other humans; sociologists term this learning 'socialization'. Socialization refers to the ongoing process of 'becoming' that is at the center of our lives; it is the process by which a human becomes a social subject, agent, self or individual in our culture (Marshal1, 2009). Butler (2015) takes this assertion further and says that the very self that is the product of socialization is not formed once or definitively but is the product of an ongoing process. While the process of socialization is typically understood as the internalization of the values and norms of a culture, Butler argues that cultural norms and values are not only internalized into the socialized self but rather they are imposed on the individual being socialized by the culture. However, socialization is not a static or one size fits all process. Race, gender, sexuality, class, historical period, nationality, place of birth, and the innumerable unique variables and particularities of each individual human are mobilized 
and active in the process of socialization. The self is not an existing state that we are born with; it is the product of our ongoing socialization.

In consideration of the way that the human animal becomes a member of our contemporary culture, Butler (2015) emphasizes the way that the production of self is fundamentally dependent on the interaction with other individuals. Butler argues that the self is in reality the product of a matrix of relations. In a similar vein, Ahmed (2004) argues that emotions are not generated or located as an internal psychological state. Rather, Ahmed argues that emotions are the product of a process of social relations that fundamentally shape and control both individual and collective bodies. Both Ahmed and Butler consider the importance of language in the collective formations of both emotions and the self. Language is a powerful force in the construction human life because, according to Foucault (1978), discourse is the way that the meaning of things, words, or social phenomenon are constructed by our social world. Discursively constructed meanings are the product of the historical and social conditions of the society in which they exist (Foucault, 1978). Furthermore, social discourse places limits on the way that discursively constructed meanings are understood.

Butler (1990) illustrates the role of discourse in the construction of our understanding of reality by problematizing our culture's dualistic distinction between the material body and the mind. Butler (1990) argues that the distinction between the material realities of the body and language is artificial because the body is defined and understood through language. Butler's consideration of the role of language in the construction and understanding of the material world is demonstrative of the power that discourse has to shape human life. Butler (2015) emphasizes that this linguistic power 
draw attention to the very moment the human animal enters our cultural world. From the moment, a human enters our social world they are categorized and labeled (girl or boy) by the already socialized subjects that surround it. According to Butler (2015), it is through the sensual interactions between members of a culture that the self comes into being. Butler (2015) questions the distinction between the idea of self and the process of socialization and argues that it is difficult to even discuss issues of the self as separate from social processes that create the self because in those discussions the existence of the social self is already presupposed.

Butler has extensively explored the implications of the self-evident nature of our identities. Butler (1990) argues that feminism itself is based on a presumption of the existence of a fundamental identity that is 'woman'. Butler explains that this identity category of women serves to create a category of people who can be discussed or mobilized both politically and linguistically. However, feminist efforts to construct the identity category of 'women' as politically and linguistically representative fails before it even starts because it discursively constructs the feminist subject within the confines of the existing discursive frames. Attempts to identify or totalize an identity category of 'women' are self-defeating because those identities are "produced and restrained by the very structures of power through which emancipation is sought" $(1999$, p. 4). Butler argues that any universal label or identity will be inherently normative and restrictive, even in the case of feminism which seeks to emancipate women from the restrictions of patriarchy. Furthermore, Butler argues that efforts to universalize the notion of woman or a feminist movement will fundamentally fail because of the intersections between gender and other repressive social structures such as race or class. Butler goes on to argue that to 
claim a universal feminism would be an act of colonization of non-western cultures by feminism.

The body/mind duality recurs in a number of places in Butler's work. Butler (2004) argues that the body/mind duality is represented in the construction of femininity as fundamentally embodied while the masculine is located in the disembodied mind. Importantly Butler points out that to question the embodied/femininity, disembodied/masculine division it is first necessary to question the fundamental proposition of the body/mind duality. One of the ways that Butler demonstrates this in her discussion of the sex/gender binary. Butler argues against the common conceptualization of sex as only that which is biological and gender as the social construct of masculine and feminine. Butler makes it clear that gender and sex are mutually informing terms, both of which are intimately connected to the social context within which the social subject exists. The link to the body/mind duality is seen in the typical configuration of sex as something biological and gender as something socially produced. Butler argues that the distinction between the material body and language is artificial because the body is defined and understood through language. In this argument, Butler is not only challenging the issue of material/language dichotomy but she is also implicitly challenging the body/mind duality.

\subsection{The Self and the Contemporary Security State}

The events of September 11, 2001 have greatly impacted the course that our society has taken in the decade and a half since. The response of many western states was to declare war not on the specific perpetrators of the events of $9 / 11$ but to declare a war 
on terror. There is an ambiguous, unstable, and ever changing discourse at the center of the war on terror. This discourse exists in a context where governments are restricting the civil liberties of some members of our society based on their apparent similarity to the imagined enemy of the terrorist. This term, terrorist, has come to have significant racial, religious and cultural associations. Appiah's (2009) racial labels framework is similar to, and a kind of application of, Foucault's concept of discourse. Whereas Foucault focused on how discourse works conceptually and symbolically in the social world Appiah, emphasizes how these conceptual and symbolic systems affect the lives of social actors. While racial groups have no fundamental biological basis, Appiah (2009) asserts that the discursively constructed labels associated with race have real effects on people's lives. The ambiguous and unstable identity of the enemy that is 'the terrorist' leads our culture to generalizations that are applied to and imposed on all members of a racial, religious or cultural group. According to Appiah, when racial labels are ascribed to individuals, they can then come to identify with those labels. Once individuals identify with a racial label, those labels are then the framework the individual will use to direct and limit the choices that they make in their lives (Appiah, 2009). Furthermore, it is important to note that these racial labels play a role in the matrix of relations that come to constitute the racialized person's sense of self. In the same way that discourse functions to create, while at the same time limit, meaning, Appiah asserts that racial labels function to both create the symbolically raced-individual while also placing limits on the behaviour and choices of that person. Memmi also discusses the adoption of a racist view of oneself and he terms this the "interiorization of racist denigration" (2009, p. 132). Foucault's conceptualization of discourse, Appiah's racial labels, and Memmi's interiorization all 
point to the power of discourse to construct or socialize the self to accept the conditions of their own oppression. All three of these processes require that the individual subjected to them learn to internalize the status that is ascribed to them by these processes. It is through the internalization of these ascribed statuses that individuals learn to perform their racial roles in contemporary society.

The internalization of racist attitudes demonstrates how the discourses that structure our understanding of the role of the state can have profound impacts on the internal ideas of self held by citizens. According to Memmi (2009), the marginalized or the minority are the ideal targets for the label of 'threat'. Memmi explains that the minorities' status as different renders them inherently suspect and thus the ideal target to be considered dangerous to the majority group. Furthermore, the designation of the threat as something outside of and other to the majority group reassures that the dominant culture is secure and right (Memmi, 2009). The identification of a dangerous other deceptively lurking within allows for the purification of the politically and culturally dominant group through the destruction of the threat (Memmi, 2009).

According to Young (2003), much of feminist theory rests on the notion that masculine domination of women is motivated by a male desire to sexually dominate and possess women. Rather than the masculine figure as the dominating possessor, Young proposes a more chivalrous masculine protector figure. In this logic, masculinity becomes defined not through the sexual domination of women for male gratification. Rather, under the logic of masculinist protection, masculinity is defined through the role of protector of the family and household (Young, 2003). The good men of the world are loving and selfless, they defend their women and children from the dangers of the world. This leaves 
the women of the family free to pursue the more "elevating and decorative arts" (Young, 2003, p. 4)). As a necessary counter to the selfless protecting male is the selfish aggressor who wishes to invade the good man's home and sexually conquer the good man's women and property; these are bad men.

The duality of good men and bad men is fundamental to the logical structure of masculinist protection. Young (2003) argues that the goodness of the good men can only be seen in the existence of the bad men; these two ideas need one another to exist as they are mutually informing and defining. A second duality present in the logic of masculine protection is the duality of good women and bad women or women worthy of protection and women unworthy of protection. Young explains that good women submit to the protection and will of the good men whereas bad women are those who resist the will of the good men and demand to make decisions for themselves; the bargain is: submit to the good man's protection and will or you are fair game for the bad men. Furthermore, Young argues, not only do men withhold protection they may also become the attacker if women do not submit to the will of the good men. In exchange for this protection, those protected are placed in a subordinate position. They give up access to critical decision making power and authority. Not only should the women and children submit to the protection and happily give up all power and authority but they must be grateful while they do it. It is that protection that is the demonstration of the woman's worth; the woman without protection is clearly a being with no value (Young, 2003).

Young (2003) proposes this logic of masculinist protection as a means for a feminist interpretation of the contemporary relationship between the security state and the citizen. Young argues that examining the war on terror and the post $9 / 11$ security state 
through a gendered lens illustrates "how a certain logic of gendered meanings and images helps organize the way people interpret events and circumstances" as well as the possible position and courses of action available to them (Young, 2003, p. 2). Young argues that the gendered logic of the masculine role of protector in relation to women and children "illuminates the meaning and affective appeal" of the current security state with its ongoing war against an ambiguous enemy and ongoing demand for the sacrifice of rights and obedience at home.

Under the logic of masculinist protection, the protected are in a subordinate position of dependence and submission; the citizens come to occupy that position in a state structured by this logic. Young argues that this subordinate dependent position of the citizen fundamentally threatens our democracy. Following the events of 9/11 the Bush administration used fear as a justification for suspending the regular rules of civil rights and due process in the United States, arguing that citizens must accept these new intrusions of privacy and liberty in exchange for necessary security (Young, 2003). A similar line of reasoning has recently been used in Canada, to justify the Harper government's Bill C51. As with the good women and bad women in the logic of masculinist protection there are good citizens and bad citizens in the security state. Those citizens who do not accept the enhanced security measures and limited civil rights of the security state are automatically rendered suspect as is the woman who does not accept the subordinate position in the household of the masculine protector (Young, 2003). The citizen who does not submit may be subject to interrogation or detention just as the non- 
submissive woman may be cast out from male protection and thus be fair game for the bad men of the world.

\subsection{Representation and Reality}

The consideration of representations is a central aspect of this project and therefore feminist understandings of representation need to be considered. According to Butler (1990), feminist discussions of representations become "inevitably caught up in a set of persistently ambivalent ontological claims (1990, p. 105). However, to deconstruct our understanding of reality is not to negate the existence of the real. Rather Butler proposes that to deconstruct the real is only to interrogate how ideas of the real are created and distributed and how that determines what comes to be known as or excluded from the real. Butler proposes that the ideas of fantasy and reality are, much like gender and sex, mutually informing concepts. The real is understood as that which is not fantasy and fantasy is that which is not real. Butler argues that fantasy is a necessary part of feminist thought, fantasy is necessary to imagine an ideal world without oppression. Butler asserts that the feminist fantasy is not not-real but rather that fantasy is not-yet real or exists as an alternative real. However, those advocating censorship of some kinds of representations have an opposite position which asserts that representation is real and has a causal link to the real. Butler argues that "this gliding from representation to the ontological claim moves in two directions at once: it establishes the referent first as that which the representation reflects and re-presents and, second, as that which is effectively performed and performatively effected by the representation." (1990, p. 185). The assertion that representation is responsible for the production of reality establishes a mutually informing relationship between the representation and the real. The real is 
named by its representation and the representation is named by the real. The representation also establishes what is the correct way to perform the real that is represented, the representation informs correct performance. Butler explains that this mutually informing relationship between representation and the real positions the real as "both before and after its representations: and representation becomes a moment of the reproduction and consolidation of the real" (Butler, 1990, p. 185). However, Butler views the mutually informing relationship between the real and representation as counter to any attempts to investigate the actual foundations of the real. If the representation is taken as the real, it is not possible to critically examine the real itself, because the real is both produced and reproduced through the representation (Butler, 1990). If the real is the product of representation, then how can the real be investigated and how can the question of what is real and unreal be addressed. Considerations of the ontological claim examine where these lines are drawn, how these borders are regulated and contested, and by whom (Butler, 1990). By understanding the real as something dependent and contingent we can examine how the real is determined by what is not-real and how that makes the not-real a fundamental part of the real (Butler, 1990).

Butler (1990) uses an exploration of the idea of the phantasmic to demonstrate how, if the real is dependent on the not-real for its meaning and identification, then the not-real becomes the very locus for the contestation of the real. Butler argues that within political discourse, the real is phantasmic in that the real is the product of a process of unequal power relations that places some states of being as superior (real) to inferior (notreal) states of being. According to Butler, (1990) even within our language about fantasy there are presuppositions that limit the true investigation of the ontological claims made 
by fantasy. The identity of the one who fantasizes is always presupposed; the dualistic status of the I who is both the author and participant in the fantasy is not questioned but taken as a given; its pre-existence is accepted and not challenged (Butler, 1990). Butler's goal is to demonstrate how attempts to limit and regulate representations of fantasy have the effect of reproducing the very fantasy that they seek to restrict. Butler argues that attempts to limit fantasy only function to further eroticize the fantasy because they offer the boundaries to be challenged. Butler argues that prohibition precedes fantasy and functions to structure it.

\subsection{Gender and Genre}

I will use the zombie as a tool to analyze the relationship between women, war, consumerism, and the cultural production of self. I will begin with a discussion of the zombie genre and some of the ways that existing feminist interpretations of popular culture have typically viewed the relationship between women and the genre. Patterson (2008) explains that much feminist theory on popular culture has focused on genres that are explicitly geared towards female audiences; however, there exists an important body of feminist considerations of the zombie/horror genre in particular. Paterson goes on to discuss some of the existing feminist interpretations of the horror genre. Feminist scholars have focused on how the horror genre reflects some of the problematic cultural constructions of women and women's bodies. Patterson outlines the important role of the good/bad woman dichotomy in feminist interpretations of horror. Williams (1984) reinterprets the horror experienced by the female viewer or character as horror at the reality of their own subordination. Williams asserts that the horror film makes the woman's subordination to patriarchy symbolically represented in the horror and violence 
depicted in horror film. Importantly Williams goes on to assert that the woman who looks away, who refuses to see the reality of her subordination, is the woman who is in the end saved from the horror depicted. The good woman looks away from the representation of her subordination, the bad woman learns the reality of her subordination. Another important interpretation of women in horror that Patterson presents is Creed's (1993) conceptualization of the monstrous feminine. Creed argues that horror film discursively constructs the female body as inherently monstrous; reproduction, lactation, and menstruation are all things that make the female body inherently terrifying and other to the male audience. Furthermore, Creed asserts that the upending of social norms in the horror film means that it is in reality the male characters that are feminized.

Unfortunately, a significant portion of the feminist consideration of the zombie and horror genres has reinforced what Patterson sees as essentializing gender tropes that view women who view the seemingly male genres of zombies and horror as passive or masochistic. However, the essentializing of the female viewer's experience as passive or masochistic fundamentally excludes women who do not view the horror or zombie genre from a negative or masochistic perspective (Paterson, 2008). Patterson's consideration of the gender genre debate is reflective of the broader struggle within feminism in constructing the category of women. The efforts to construct and identify the audience for any given cultural product will inherently exclude some of that product's viewers. Just as Butler explains, the attempt to create a politically active and identifiable category of 
women will inherently fail in this endeavor because once the category is created it immediately excludes some individuals.

\subsection{That Which Lacks Self}

Lauro and Embry (2008) assert that the zombie is one of the most common monsters in contemporary culture. The contemporary zombie has roots in Haitian folklore. In Haiti, the zombie was a human corpse raised from the grave by a Voodoo Priest to work in the fields (Lauro \& Embry, 2008) (Dendle, 2007). The Haitian zombie was the ultimate nightmare of slaves, as even death would not be an escape from the slave labor of life (Lauro \& Embry, 2008). Furthermore, the zombie is a representation of our own slavery to our mortal bodies; the zombie's dead state is ultimately the fate of us all (Lauro and Embry, 2008). However, the zombie is an extremely malleable cultural symbol. The meaning of the zombie has changed over time. Even within Haiti the zombie came to take on additional meanings. According to Lauro and Embry (2008), following the slave revolt in Haiti the zombie came to represent slave revolts as opposed to slaves themselves. Colonial reports of the rioting slaves in Haiti describe them in terms that would be familiar to fans of popular zombies: "fanatic and insensate hordes of blacks rose as a single body to overwhelm the more 'rational' white troops" (quoted in Lauro and Embry, 2008 p. 98). So, the zombie early in its evolution came to represent two sides of an apparently dichotomous relationship, indicating the zombie as both slave and slave rebellion (Lauro and Embry, 2008). A wide variety of human anxieties can be interpreted through the lens of the zombie; for this reason the zombie is a useful metaphor when considering the ways that popular culture reflects the anxieties of the culture at large. Dendle connects the zombie to a variety of contemporary sources of 
cultural anxiety such as environmental degradation, political conflict, and biomedical science. Saunders (2012) connects the zombie to post 9/11 security anxieties related to the blurred boundaries of globalized of geopolitics.

The interpretation that I was most familiar with at the outset of this project and the one that most directly drives this project is the zombie as critique of consumer culture. This consumer zombie is most directly and explicitly connected with the work of George A. Romero (Bishop, 2010) (Dendle, 2007). Most of the action in Dawn of the Dead takes place within an abandoned shopping mall where the human characters of the movie have taken refuge. For Bishop, the connection to consumerism is twofold in Dawn of the Dead: The zombies themselves are perfect embodiments of consumerism; they are dead and yet they are relentlessly driven to consume in this case, to consume the flesh of living humans. Bishop argues that zombies are a symbol that reveals the "true problem infecting humanity: pervasive consumerism” (2010, p. 235), Bishop explains that Marx conceptualizes meaning in human life as originating from productive labor. When productive labor is removed from human lives they lose their source of meaning or as Marx puts it their species being. Bishop (2010) emphasizes the loss of humanity's species being as the true crisis of Romero's story. The truly clever insight of Romero's film is that this species being has already been lost prior to the zombie apocalypse. Before the outbreak of the zombie apocalypse these humans were already zombies to consumerism. Human life prior to the zombie apocalypse was structured around endless cycles of consumption and as a result these places of consumption such as shopping malls have become focal points for the zombie hordes (Bishop, 2010). Furthermore, the humans within the mall become heavily invested in the consumer products contained within the 
mall and ultimately seek to protect what is theirs from a group of marauding humans who come to see what they can find in the mall. Bishop (2010) argues that the humans in Dawn of the Dead have lost their purpose in life because of the collapse of civilization and the economy. The human characters in Dawn of the Dead are unable to see their new world "in any terms other than those of possession and consumption"; they have completely lost their species being and are trying to fill the void with the consumer goods contained within the shopping mall (Bishop, 2010, p. 235). However, this is a futile and empty effort on the part of the humans as this consumption can create no meaning.

Dendle interprets the bacchanal of consumer pleasure that the survivors engage in as lacking meaning for a different reason than the interpretation offered by Bishop. Dendle argues that the consumption of the human figures in Dawn of the Dead is rendered meaningless because of its disconnection from any larger structures of social meaning. The pleasures of consumption do not have meaning if they are not shared with the larger community of individuals that would normally partake in those consumptive practices. Dendle's explicit connection between meaning and the "dynamic network of friends, family, or society" demonstrates how consumptive practices are an appropriate point of examination when investigating the self as a product of a matrix of relations (2007, p. 51).

As already mentioned, zombies are an extremely malleable monster, they can take many forms and be linked to many different causes reflecting a variety of contemporary anxieties. Zombies can move fast such as in the film 28 Days Later, or slow like the zombies in Romero's films. They can be caused by a virus or their cause can be completely unknown. Sometimes causes are an important part of the mythology of the 
story, other times they are not. Importantly there is a commonality to all zombies: they are dead. Even in their origins in Haiti they are dead raised from the grave to walk the earth again. However, there is an important distinction to be made between the zombie and other extremely popular undead monsters such as vampires; that is, zombies have lost all vestiges of their human consciousness (Lauro and Embry, 2008). A vampire retains its human consciousness, awareness and will whereas the zombie represents a different kind of horror, a "primal fear of losing the self" (Lauro \& Embry, 2008, p. 89).

\subsection{Denaturalizing \& Destabilizing the Object/Subject Binary}

According to Jones (2013), the zombie denaturalizes and destabilizes the apparent boundaries that structure our social world; this destabilization and denaturalization allows us to call various aspects of our sociocultural condition into question. Even the most basic and fundamental boundary - that between life and death - is blurred by the zombie so fundamentally that, as we will see, the subject or object status of the zombie becomes unclear. Jones (2013) discusses the film Deadgirl, which revolves around a group of high school boys who find a zombie woman chained in the basement of an abandoned asylum and decide to use the zombie woman as their own personal sex slave. Jones begins by discussing the presence of rape in popular culture, how rape is a common feature of our popular culture and has achieved a level of what he calls representational acceptability. Jones discusses how and why censors, particularly in the United Kingdom, decide which movies to censor because of depictions of sexual violence and why. Deadgirl was not censored in the United Kingdom despite the fact that the female zombie was restrained and the male protagonists repeatedly sexually violated this restrained zombified woman in the film. Jones argues that the censors in the United Kingdom did not see the sexual 
violation of the titular Deadgirl's body as an act of rape because of her dead status; Deadgirl's dead status rendered her an object rather than a subject therefore making the sexual acts against Deadgirl not acts of rape but rather acts of necrophilia. However, even an act of necrophilia is seen as a violation, in that it is a violation of those still living who love the formerly living person (Jones, 2013). Jones argues that there is something particular about Deadgirl's status as a zombie that makes her violation fundamentally different from the violation of a normal human corpse.

Jones also analyzes the special features that accompany the DVD release of the film Deadgirl; of particular interest is the commentary of the film's writer, Trent Haaga. Jones argues that the writer's attempts to defend his film against criticism demonstrate how the zombified Deadgirl in the film so effectively breaks down the binary between the zombie object and the zombie subject. Haaga attempts to argue that the film would not have been met with the same criticism had the object the boys had found been a shapeless blob from space with various fuck holes (Jones, 2013). Problematically of course for the space blob Haaga's assertion fundamentally privileges the boys who are fucking the space blob rather than the space blob being fucked with identifying exactly what is a fuck hole (Jones, 2013). The same is true of Deadgirl; she does not identify any of her holes as fuck holes and it should be noted any hole that exists in Deadgirl is a valid fuck hole for the boys who find her be they orifice or wound (Jones, 2013). However, at one point Deadgirl injures one of her male attackers and he subsequently turns into a zombie himself. At no point do any of the male zombie's various holes become fuck holes. It is only the female zombie Deadgirl whose holes are valid fuck holes. Jones (2013) argues that it is Deadgirl's gender than renders her holes into fuck holes and also that it is her 
gender that fundamentally transforms her from an object (blob) into a subject (girl). If Deadgirl were truly an object then the male zombie would be an equally valid target for sexual exploitation as he has holes for fucking just as Deadgirl does. However, this does not happen because the male zombie is not simply an object, he has a gender and is therefore a subject. Furthermore, Jones notes how the young male characters in the film describe Deadgirl as unwilling; this ability of the protagonists of the film to themselves ascribe will to Deadgirl, and therefore the ability to violate that will, fundamentally mark their acts as sexual violation and acts of rape and not necrophilic acts with a corpse with no will. In the case of Deadgirl her status as a zombie blurs the boundary between the living and the dead at the same time as the line between object and subject is fundamentally blurred.

The conceptual importance of visibility and the male gaze reinforces the previously stated subject-object dialectic: are women subjects who consume as agents or are they objects for consumption by male agents in a consumer culture? Just as Deadgirl fundamentally blurred the subject-object binary, women in our consumer culture have the power to do so as well. Cronin (2000) argues that the relationship between women and consumerism has long been an ambiguous one which places women in the position of both object and subject, where women are both agents of consumption and a "commodified currency in capitalist exchange" (Cronin, 2000, p. 283). Cronin explains that the "majority of domestic consumption practices such as shopping" are carried out by women and that the domain of consumerism has been historically seen as feminine. However, this is to be contrasted with the reality that our consumer culture is based in discourses of Enlightenment rationality and individuality which fundamentally exclude 
women (Cronin, 2000). The individual, which is so central to our culture, is "an exclusive and politically privileged category" that is restricted to able-bodied adult white middle class males (Cronin, 2000, p. 274).

In a consumer culture, it is through consumption that the self is produced; subjectivity is achieved through consumption (Cronin 2000). Furthermore, as Butler (2009) explains, the anti-racist Paris riots of 2005 which attacked property rather than people were still conceptualized as acts of violence. The conceptualization of vandalism as violence or violence against an object seems only possible in a consumer culture where the products and objects consumed come to represent and identify the person. This recalls the world of Romero's Dawn of the Dead: both its humans and zombies are drawn to the consumer hub of the shopping mall. In the Dawn of the Dead the humans trapped in the mall search for meaning in the post-apocalyptic world amongst the consumer objects contained in the mall.

\subsection{Zombie Women}

According to Cronin (2000), women, by virtue of their exclusion from the white heterosexual male demographic, are incapable of being individuals. This is logically similar to a key distinction that Lauro and Embry make between the zombie and other undead monsters in our popular culture: zombies have lost all vestiges of their human consciousness or self. In our consumer culture, women straddle a boundary where they are consumers and therefore subjects in a consumer culture but they are also fundamentally epistemologically excluded from the privileged status of individual. The individual has an absolutely primal status in our culture: to be an individual is to be. Yet 
this is a status from which women are excluded by culture. The boundary-straddling woman of consumerism is like the zombie described by Lauro \& Embry, as she is symbolically lacking individuality, the most basic aspect of personhood in our culture.

The ambiguous cultural status of women is a reality that I and all women in our culture live with. I am a highly sensitive person, and my intellectual engagement with these issues always takes place in the context of my emotional understanding of the world. I find it extremely easy to immerse myself in the experience of another human being if I talk to them about their experiences. I feel their emotions very powerfully when I communicate with people about emotional topics. Emotions are very much at the surface of everything in my life. My emotional experience of the world is such that at times it causes me to not be able to properly function socially in our culture. At times even the observational reflective methodologies that I have chosen to employ have been emotionally difficult for me. Even growing understanding of the realities of my own symbolic and discursive status can cause emotional turmoil for me. Research that involves interviewing and interacting with human subjects would be extremely emotionally costly for me. Rather than see my emotional engagement with my research subject matter as something that impedes my generation of knowledge about our culture, this project places my own particular subjective personal experience at the heart of my methodology. The current project is an examination of what our entertainment choices tell us about the culture that we live in. More specifically this project is an investigation of the reflexive relationship between the self and popular culture. Importantly, I have attempted to craft both a theoretical perspective and methodology that mobilizes my intense emotional engagement and experience of the world as a strength, allowing me to 
carefully examine some of the ways the popular culture that I consume is integrated into myself. I have developed my analysis using two methodologies that I believe complement one another and lead to a varied and rich foundation for my conclusions. I have combined an ethnography or webnography of online fan cultures with an autoethnography of my own personal experience of being an academic who is also a fan and conducting a webnography. I will turn now to the way that these two methodologies have come together through the completion of the project to created phronetic knowledge about the role of popular culture in the contemporary construction of the self. 


\section{Chapter: Becoming the Zombie Autoethnographer}

\subsection{Being the Autoethnographic Webnographer}

Webnography is a practice that lends itself immediately to market research. This is reflected by the fact that much of the research that uses webnography is available from market research journals. However, the internet is not just a tool for facilitating connection between marketers and consumers. The internet is also a lived in social space where people interact with the culture at large (Puri, 2006). Not only has the internet changed the way that we communicate, Puri argues that the web is one of the catalysts of globalization. The internet has made the contemporary cultural landscape a much smaller place. Communication between geographically distant people has been hastened and facilitated like never before. However, Perry and Olsson (2009) warn that the internet also facilitates the linking of racist and other extremist individuals and groups. The virtual spaces and communities of the web are not bounded by geography or nation states and constitute a new space and new way for individuals to connect not only with other agents but also to connect with the cultural products with which the users are engaged. A webnography looks for the insights that are generated by these communities and connections themselves (Puri, 2006).

Hine (2011) argues that the internet has necessitated a move towards a broader site of study in ethnography. Hine asserts that there is a growing recognition that the bounded specific research location that is privileged by traditional ethnography is a construct that has little connection to the way that people live their lives. Hine argues that because society is complex, a complex and varied source of data will offer insight into 
that complexity. Both Hine (2011) and Puri (2006) emphasize that webnography offers the researcher a position of complete invisibility. The goal of traditional ethnography is to disappear into the surroundings and observe without influence; this goal can be easily achieved through the examination of public forum discussions online. The internet also has extensive archiving of materials so comparisons can be made between past discussions and those happening in the present. It is here that the process of hybridization between the two methodologies begins. I would like to emphasize again that both Puri and Hine see the online social world as a genuine lived in and experienced social space. This view of the online social world as a lived in social space is the idea that ultimately guided the hybridization of my two methodologies. The goal of my webnographic endeavor is not to describe the online fan culture. It is through the application of an autoethnographic filter to the methodology that I transform the webnography into an account of my own personal experience of that culture. By placing my own self at the center of the methodology I am able to use myself and my experience as the means of identifying the relevant webnographic data.

\subsection{Selecting and Collecting Data}

Hine (2011) advocates a broad base for webnographic research. Hine used readily available sources found via search engines to conduct her webnography of fan cultures of the series Antiques Roadshow. I found my sources in the same way as Hine. For the eight week period when the first half of the sixth season of TWD was airing, I lived as a fan in a selection of online environments specifically dedicated to TWD. I only observed these environments. I contributed to no conversations and created no user profiles. All of the information viewed on the communities described was publicly available without login. I 
decided on the use of a variety of different websites as the sources for my webnographic cultural experience because it offered a complex and varied picture of the online fan community that I am mobilizing for this investigation. I regularly visited and collected screen shots of pages on $\mathrm{r} /$ thewalkingdead (Reddit, n.d.), the subreddit dedicated to the series The Walking Dead. Because Reddit is an all purpose discussion and image forum, it offers access to a wide base of users who can come to Reddit for any number of reasons.

Reddit illustrates some of the complex ways that the fans integrate the story and characters into their selves and their understanding of their world. The Walking Dead subreddit, particularly around Halloween of 2015, featured numerous examples of fans in costume as their favorite character. In these examples the fans are literally putting on the characters from the series, pretending to be them for an evening, event or photograph. The Reddit response to the first episode of season six demonstrated how the fans of cultural products also use those products to understand and create meaning about events in the world. The season six premiere featured a 'herd' of zombies, the size of which had never been seen on the series before. There was a particularly poignant observation by Reddit users of the similarity between some of the imagery contained in the episode and the ongoing European refugee crisis. The user placed side by side a screenshot from the episode of an overhead shot of the herd of zombies moving through the countryside and aerial photographs of crowds of thousands of refugees moving through Europe. This particular observation by the fans demonstrates how the fans, understanding of not only themselves but of their world is an ongoing process of meaning production. The way that an agent understands their world is the result of a process of meaning making in which 
the fans make emotional connections between the fantasy world they are watching and the reality of the world around them.

I personally found the format of Reddit somewhat difficult to understand without existing knowledge about how the Reddit system and community operates. The online community known as thewalkingdeadforums.com (The Walking Dead Forums, n.d.), is a website dedicated specifically to the series. I was much more familiar with the layout and organization of thewalkingdeadforums.com. Thewalkingdeadforums.com has specific sections of the website dedicated to exploring different aspects of the series.

Thewalkingdeadforums.com has sections dedicated to both the television and the print versions of the series, a section on general zombie discussion, as well as a section dedicated to the spinoff series Fear the Walking Dead. There are organized discussion areas for each season, episode and character. There are also sections for fan predictions, theories and spoilers. Thewalkingdeadforums.com even has specific spaces dedicated to some of the ways that fans can inhabit their favorite characters and stories featuring sections for both Fan Fiction and Fan Art. Thewalkingdeadforums.com also features a number of other general discussion forums for users to discuss other topics or entertainment products. For the duration of the first half of the sixth season of TWD I visited and collected data from these websites. I allowed myself to explore the communities as I saw fit. I captured all threads that I found interesting or to which I had a significant emotional reaction. I captured hundreds of pages of discussion from these communities over the eight week data collection period.

I also attempted to explore the discussion forums on the website for AMC, the network that produces the series. However, the forums on the AMC website were 
difficult to capture from a technical perspective in terms of gathering data. The AMC website was also very difficult for the users actually trying to use the forums. For this reason, I abandoned my consideration of the AMC forums early in the data collection process. I had also initially considered including webnographic data from popular cultural media sites as the articles produced by the media outlets would be commented on by internet users. However, I decided that I did not want to colour either my fan or my academic experience by the analysis conducted by these media outlets.

Puri and Hine both address some of the limitations of webnography as a research methodology. A great deal of the discussion of limitations for both Hine and Puri focuses on issues of the authenticity of the webnographic subjects being researched. Puri examines issues of authenticity and representativeness from a marketing perspective: do those who are vocal online represent the average consumer? Puri notes that you can make demographic conclusions about the users of the online forums studied. The demographic information about the group active on your forums will help dictate what kinds of groups and products can be studied. This concern about the validity of webnography as a research methodology is rooted in a view of its purpose as the generation of knowledge that functions to facilitate connections between marketers and consumers.

The societal importance of understanding the operation of online cultures beyond facilitating consumer relationships can be demonstrated by examining some recent developments in online fan cultures. Fan culture, particularly fan culture online, has become a very perilous place for women. Women, such as cultural critic Anita Sarkeesian and game developers Zoe Quinn and Brianna Wu, are seen as intruding on the typically male space of gaming, and have become the target of terrifying campaigns of 
harassment and intimidation known as Gamergate (see (Sarkeesian, 2015), (Parkin, 2014), (Lewis, 2015) and (Wu, 2015)). My own critical/academic interest in the television series The Walking Dead also places me in this potentially intruding position as the series has its roots in the typically male environment of comic books. The public campaign of harassment faced by women in the video game industry limits the ability of diverse voices to express themselves, particularly in the public sphere of the internet. The rejection of female voices from the video game industry is further reflective of the importance of the relationship between power and knowledge. These women who had apparently transgressed the gender boundary of gaming didn't see themselves represented in the entertainment forum that they were a fan of and so they tried to voice their desire for inclusion. These women, who were seen as intruding on the traditionally male gamer identity, were demanding to be a part of what is known as a gamer. I am also personally familiar with the trepidation associated with online participation as a feminist and a woman. Before the controversies of Gamergate I was afraid to express myself in the public sphere of the internet. However, it was in a time of great personal turmoil that I started to confront this fear and began to publish my writing in a personal blog. Ultimately, I'm inclined to think that while there are risks involved in joining the online world there are important reasons that this kind of engagement should be pursued. It is liberating. There is a need to be heard by the world. A plurality of voices help make up the meaning of the things in our world and our lives.

I initially viewed autoethnography as a counterbalance to the anonymity and apparent inauthenticity of the internet forums I was exploring webnographically. The 
work of Ellis (2004) has fundamentally shaped the development of autoethnographic methodology and demonstrates that autoethnography is not a means of achieving authenticity in qualitative research. Autoethnography is both the method of investigation used by the researcher but it is also the product of that research (Ellis, Adams, \& Bochner, 2011). Ellis, Adams and Bochner describe autoethnography as a writing and research approach that seeks to "systematically analyze personal experience in order to understand cultural experience" (Ellis, Adams, \& Bochner, 2011, p. 1). Furthermore, autoethnography combines aspects of both autobiography and ethnography. Ellis et al. explain that autoethnographers reflect on their experience looking for what can be seen as epiphanies or moments of great change or rupture in life. A particularly useful understanding of the ethnographic aspects of autoethnograpy views ethnography as the investigation of "a culture's relational practices, common values and beliefs" (Ellis, Adams, \& Bochner, 2011, p. 7). Furthermore, this understanding of ethnography as relational practices is not limited to the interrelationships between speaking or acting individuals but also considers the cultural use of space, consumer goods such as clothing and cultural products such as books, movies and television (Ellis, Adams and Bochner, 2011).

The true purpose of autoethnography for this project is to examine the way that I integrate the popular cultural products that I consume into my sense of self. The internal reality that the self exists in is fundamentally structured by a collective representation of reality that is language, that is, our thoughts use language, 'I think therefore I am' (Butler, 2015). The relationship doubles back on itself when we consider the way that the self understands its relationship to the cultural reality. Moreover, the collective reality of 
culture is not an objective state. The collective reality created through connection with other humans is infected with power and inequality and does not give equal power to all voices (Foucault, 1979). The self understands its position of power relative to the other players in the collective culture and conducts itself according to its relative position, thus reproducing its own conditions of status (Butler, 2015). The hybridization of autoethnography and webnography demonstrates how the relationship between these two realities, the internal reality of the self and the reality of culture, is reflexive.

Autoethnographers look for the moments of synergy between personal moments of epiphany and broader cultural phenomenon. These moments of synergy offer insights into both the self experiencing them and the broader culture (Ellis, Adams, \& Bochner, 2011, p. 8).

Ellis et al. (2011) offer a variety of forms and approaches to autoethnography. For this project, I will focus on two of the approaches outlined: Narrative ethnography and Reflexive ethnography. Narrative ethnographies attempt to create a story that incorporates both the ethnographer's own experience and their observation and analysis of others. Reflexive ethnographies consider the way that the experience of doing the research changes the researcher themselves. My autoethnographic webnography is a consideration of how my experience of investigating the relationship between the self and popular culture is productive of not only knowledge about the self but also produces the hybrid fan/academic self. The final stage in the deveopment of the methodology for this project was completed and understood only once the final writing process began. The role 
of writing as a method of inquiry will be considered in the final discussion of methodology for this project.

\subsection{Futile Devices}

We do not live in an oral culture. I am good when I speak. My ability to use language when I speak is outstanding. There is a clarity of understanding necessary when you communicate with written language as opposed to oration. Despite my own lack of confidence in my ability to execute written communication it always and inevitably leads to a different or deeper understanding of the topic I am writing about. Unfortunately, as a part of my struggles with mental illness, I get into a space where I cannot even begin to put word to page unless I have every word planned and perfected. I don't want to see the marks on the screen/page until I know they are the perfect words that perfectly capture the complexity of the experience that I am attempting to describe. This intense emotional relationship to language is present in every endeavor that I undertake involving the written word. In reality the perfection of representation I am seeking is an absolute impossibility. Language is the crude tool that I am attempting to utilize to describe or capture the entire complexity of human experience, or in the case of this thesis one particular aspect of the contemporary socio-cultural condition. I need to accept and acknowledge that my words will never be able to completely capture all of myself or my feelings. I need to accept language for what it is, the meagre tool I have to communicate my emotions and experience of the world.

The final step in the methodology of this project is related to overcoming or addressing my intense emotional engagement with the writing process, something that I 
was attempting to convey with the introduction to this section. Richardson (2004) is critical of the positioning of writing as an end product of a given methodology. Richard asserts that the positioning or conceptualization of writing as the end product of research privileges and is designed for the representation of quantitative data. Furthermore, Richardson (2004) argues the understanding of the writing process as the end task of representing the research is rooted in a specific view of the nature of knowledge and the scientific production of knowledge. Richardson asserts that developing researchers are taught that the writing process begins when you know what it is that you as a writer want to say. However, as Richardson explains and as I very clearly experienced when completing this project, the process of writing the research is in reality a vital part of the research process itself. Richardson argues that this conceptualization of writing as the mopping-up at the end of the research project is reflective of what she describes as a broader "sociohistorical invention that reifies the static social world imagined by your nineteenth-century foreparents" (Richardson, 2004, p. 474). Richardson is referring to the differential and hierarchical cultural relationship between science (described in the theory chapter of this project) deemed to be hard science or physical science and the so called soft sciences of the social science. Richardson argues that the positioning of writing as a final clean up process at the end of research functions to eliminate the individuality of the researcher from their project in the pursuit of objectivity.

Based on Richardson's (2004) problematization of the dominant conceptualization of the role of writing in the research process, I was able to reconceptualize my task as a writer as a means to undermine the intense emotional weight that I place on my writing. I have repeatedly throughout this project emphasized its 
selectiveness, the uniqueness of the findings or analysis contained herein. Richardson clarifies my reliance on this catch all methodological mea culpa as the product of a postmodern culture of doubt that casts all knowledge as contingent to the influence of institutionalized and historical relations of power. Richardson proposes that this postmodernist context of doubt lets qualitative postmodern writers "off the hook, so to speak" (Richardson, 2004, p. 475). I would like to observe that Richardson does not dismiss the importance I personally place on the writing process. Richardson outlines how our linguistic understanding of the social relationships in our lives influences our subjective experience of them. Richardson acknowledges and accepts the power that words have but also undermines any idea of permanence in their meaning. As I explained, Richardson (2004) sees the typical conceptualization of writing as the endmopping-up after research has been completed as a way for the individuality and self of the writer to be eliminated from the research. Richardson argues instead that the view of writing as a method of inquiry allows the researcher's self to be reintegrated into the research. Furthermore, Richardson proposes that language and the act of writing research is an important part of the way that we construct our sense of ourselves as researchers. This assertion is very much reflected in my own experience as a researcher. As I said at the very beginning of this project, life does not always proceed the way that we expect it to. The execution of this project was interrupted, and redirected in catastrophic ways more than once. I experienced a mental health crisis which interrupted the progress of this project. Just as I returned to this project I experienced the loss of all of my belongings in an accidental house fire. As I will discuss in the subsequent chapter (Chapter 4), I found a powerful resonance between my experience of leaving Alberta and 
the experience of the character Lori during the zombie apocalypse. However, the experience of losing all of my belongings in a fire greatly affected the analysis of both that event in Lori's story and how I understood my relationship to that part of the story. This is a moment where my own personal understanding of this popular cultural text changed and developed a new meaning because of my changing life experiences. It is important to note here that this growing and shifting understanding of myself, my life and the popular cultural texts I consume are all a product of an ongoing process, they are not static or stable but part of the ongoing creative process that is the self.

This chapter has attempted to demonstrate how this process of hybridization between two ethnographic methodologies facilitated this project's investigation of the self. My investigation of the self has been achieved thorugh a ethnographic consideration of the self. The webnographic elements of this project helped to refine and identify the valuable points of resonance between my life, the popular cultural products that I consume and the broader cultural experience of the online fan community. The understanding of the self as a product of a matrix of relations that includes the consumer objects that inhabits our life is reflected and demonstrated by this change in my own understanding of my life, and its relationship to the popular cultural institutions that are a part of that self as an ongoing creative project or experience. There is no stable self that exists and is maintained constantly throughout the objects that inhabit my life. The meaning and sense of self that is contained in those objects is living and changing at all times. The is no point at which the project of life is concluded and can be written up and 
presented as findings. The process of writing is situated in the project of life and they are both ongoing, creative and ultimately open-ended. 


\section{Chapter: Ordinary Apocalypse: A Story about Women}

This chapter will begin to reframe and reinterpret the story told by The Walking Dead (TWD). I begin this reinterpretation by acknowledging its incompleteness, and its selectiveness. The story reinterpreted here is not intended to recap the entirety of the story told in the series. Nor will this chapter address all of the important social issues to be addressed through academic consideration of the series. My analysis and interpretation of the series will be shaped by my own emotional engagement and identification with the characters of the series. It is more accurately a story about my own emotional and intellectual experience as both an academic and as a fan of this series.

With this chapter I will begin to explore the way that my emotional and academic engagement with this series has facilitated a richer understanding of my own life and sense of self. Furthermore, this chapter will consider how my emotional engagement with the series guided my intellectual and academic engagement with the series. I believe that my own experiences of disruption are a significant part of what makes the storytelling of TWD so compelling to me. My careful emotional and academic consideration of the series TWD has led to increased understanding of many of the events in my own experiences. Furthermore, consideration of my own life will serve as the basis for an exploration of the nature of the phenomenon of apocalypse. I will explore significant ruptures in my own life in order to consider: what is an apocalypse? I will use my own emotional engagement with the series to expand the idea of apocalypse to more ordinary or quotidian aspects of life. I will interpret the story arc of Lori and Andrea to explore some of the ways that the post-apocalyptic world of TWD relies on a logic of masculinist 
protection to discursively and symbolically create a subordinate feminine identity, self or position for the characters Lori and Andrea. I will consider the way that these two characters either accept or reject the identities or roles available to them in the world of TWD. I will discuss how the post-apocalyptic feminine self created for the characters Lori and Andrea in the world of TWD limits these female characters to roles that support and serve to facilitate the character development of the male characters in the show. Furthermore, I will consider how my emotional and intellectual understanding of the story arcs of Lori and Andrea is inherently influenced by of some of my own experiences.

\subsection{The Beginning Unseen: How I Got Here}

Cataclysmic ruptures in the operation of society and human life occupy an important part of our collective imagination. Across many cultures there are legends and stories of catastrophic events that alter the course of history. Some people take this as evidence that such great cataclysms must have happened in the past. However, I think the more interesting question to ponder is, why do cultures tell these stories? What need or function do stories about cataclysmic events serve? While that is not the immediate question being addressed with this project, I begin this story ten years prior to the beginning of either TWD or this thesis, with just such a cataclysmic rupture: the events of September 11, 2001. I use this temporally remote starting point because it introduces an event of disruption and destabilization at the foundation of my self narrative that is at the center of the project. The events of September 11, 2001 have greatly impacted not only our contemporary understandings of security and war, they have also had an effect on art including popular culture. I approach this analysis with an understanding that both 
governments and popular culture are part of the same system of meaning production and therefore historical circumstances matter to both pop culture and governments. Furthermore, beginning with $9 / 11$ allows for consideration of the way that this culturally destabilizing event directly impacted the course of my own life.

Importantly as a white woman in a white supremacist culture, the way the events of 9/11 impacted the course of my own life is fundamentally different from the effects that those events had on the lives of racialized populations. As an autoethnographic researcher, I am limited to consideration of only my own experience. However, this project, or more accurately my overall project of becoming my academic self, has directly impacted my understanding of my own role and understanding of the cultural and governmental developments since 9/11. I am a white woman born in a small Central Alberta town. My family was working class; both of my parents, neither of whom graduated high school, worked outside of the home. My father was a postal worker and my mother a retail clerk. Beginning about age seven, I was responsible for the care of myself and my younger sister in the summer while both of my parents worked during the day. My father's large family had lived in the same small town for generations. My paternal grandfather was the town milkman until the time of his death, and according to my family was the last person in Canada to do so with a horse and cart. While my class status did have some significant impacts on my life as a child I was also blessed with a number of advantages. I am white and I was born into a white community and this status 
has fundamental privileges in our culture. Furthermore, I won the 'birthright lottery' by being born in the economically and politically stable country of Canada (Shachar, 2009).

The news media landscape at the turn of the millennium and still today is focused on the spectacular. The events of $9 / 11$ were undeniably spectacular in their execution. The image of a commercial airliner crashing into one of the most recognizable building complexes in the world was striking because prior to that event such destruction and devastation had only been inflicted on New York City in entertainment. The spectacular nature of the attacks is a significant part of what made them so powerful (Slocum, 2011) describes $9 / 11$ as a media event in and of itself. My own memory of that day is fundamentally tied to the media. Alberta, where I lived at the time, is on mountain time, two hours behind New York City, so my mother woke me abruptly and early saying that 'America is under attack'. I then watched the morning's events play out on NBC while Matt Lauer narrated the images. For the remainder of the day every American television station had a repeating loop of the events that had occurred that morning. The events of 9/11 were perfectly calibrated to cause the maximum communicative impact in the culture that was the target of the attack (Slocum, 2011).

The remarkable degree of privilege that I have in our contemporary society can be illustrated in the way that the events of 9/11 fundamentally altered the course of my own life. I did not become subject to additional security measures or suspicion. In the fall of 2001 I had been out of high school for a little over a year and was just enjoying life. My partner had applied for jobs within the Canadian government but there was little prospect of being hired in Ottawa prior to 9/11. Following the events of September 112001 a number of Government of Canada departments received an influx of resources in the 
form of funding and newly hired staff. As a result of the surge in funding that some government departments received, my partner's application and security clearance were both fast tracked. I was invited to move to Ottawa with my partner and in February 2002 I arrived in Ottawa and began my life here. I began my undergraduate education in 2003, something that no one on either side of my extended family had ever done before. My partner continues to work for the government of Canada.

I mark my sudden departure from my life in Alberta as the first ordinary apocalypse that I experience in this narrative. It is important here to discuss why I see this event as an ordinary apocalypse. As outlined in the theory portion of this project, the self or the identity that we carry with us is the product of a matrix of relations (Butler, 2015). As previously outlined, the self is not an internally or preexisting state or center; rather it is the product of the relationships that we as individuals have with other members of our social world. It is this understanding of the self or identity as the product of our social relationships that leads me to conceptualize my move from Alberta to Ottawa as an apocalypse. At the time of my move from Alberta to Ottawa I was still living in my family home. The parental, familial and friendship relationships that had constructed and created myself were all left behind very abruptly. I don't think that every person would come to see such an event as an apocalypse. However, as was discussed in the theory portion of this project, disruptions or disturbances of the self are a feature of a number of mental health issues. My sense of self is fundamentally unstable. In periods of emotional turmoil my own sense of self becomes lost or displaced. Once emotional turmoil has passed I am left with an empty hollow feeling. I am left with a feeling of having no center, no home base to return to once the turmoil has passed. I have not always 
understood this feeling of emptiness as a lack of stable self; this understanding is something that developed over many years of therapy, and academic consideration of the idea of the self. Because there is a particular instability in my own internal sense of self I look to many things in the external world to define and stabilize my sense of self. It is for this reason that I view my abrupt move from Alberta as an ordinary apocalypse. I am a person who has a sense of self that is fundamentally tied to things external to myself. However, with my move from Alberta I left behind every relationship that had constituted and created the person that I was. I arrived in Ottawa and now had only one relationship to stabilize my sense of self: my relationship with my partner. The self that was reconstructed in Ottawa could not be the same self that existed in Alberta because it is the product of a different matrix of relations. I have been in Ottawa for fourteen years and I still experience significant disruptions in my sense of self every time I visit Alberta. Waiting to board a flight, I am always filled with dread because I feel like the person who is in Ottawa is not the same person who will step off the flight in Alberta. Because my sense of self is so unstable when I return to my family and friends in Alberta I revert to patterns of behaviour that are consistent with the matrix of relations that I have in that location. I then return to Ottawa and have to reconstruct the self that exists here.

\subsection{Not The Stars: The Story of Lori and Andrea}

The television series The Walking Dead takes place in a world that has been destroyed by a zombie apocalypse. The original series TWD does not explore the actual progress of the zombie apocalypse, although a companion series entitled Fear the Walking Dead does explore the initial days of the zombie apocalypse. The story told in 
TWD begins after the zombies have destroyed civilization. Lori is a thirty-something woman from the southern United States. Lori's husband, Rick, is a police officer who was shot while on duty and is in a coma at the local hospital before the unfolding of the events of the zombie apocalypse. When the zombie apocalypse occurs, Lori is assisted and protected by Shane, who is Rick's best friend and fellow officer. Shane wants to move with Lori and her son Carl to a safer location than their small town. However, wanting to be close to hospitalized and unconscious Rick, Lori refuses to leave the town. In order to make Lori leave, Shane lies to her and tells her that Rick has died at the hospital at which time Lori relents and agrees to travel. Shane and Lori begin a romantic relationship after Shane tells her Rick is dead.

While the apocalypse that disrupted Lori's life is more dramatic than the apocalypse of my move from Alberta to Ottawa, they share some key elements. Firstly Lori's matrix of relations is disrupted: she loses her husband and, as we learn later, her parents. Furthermore, Lori departs her home with a man; similarly, I departed my home with my male partner. Both Lori and I left behind one matrix of relations while taking on another with a man who was leading the way.

As discussed in the theory chapter, this matrix of relations need not be limited to the human relationships; I conceptualize our consumptive practices as a part of that matrix of relations. The cultural products and goods that we consume do not exist independently of the human subjects who produce, sell and consume them. My consumption of either consumer goods or cultural products brings me into relations with both our consumer culture and with the other consumers of those products. The presence of material or cultural artifacts in the construction of the character Lori is also present in 
TWD. After Lori has left her home, Rick arrives at the house having awoken from his coma in the hospital. It was the lack of photo albums in the home that made Rick believe that Lori and their son Carl were still alive. Rick believed that only a living Lori would take the photo albums. While the 'ordinary apocalypse' of my departure from Alberta was not traumatic, violent or dangerous, as the experience of a war or natural disaster would be, there are still some powerful ways that the imagined world of zombie apocalypse has resonance with this particular moment of my life. Like Lori, when I packed my few belongings, even if I didn't understand it at the time, I was leaving behind many of the things that made up my life and identity prior to that time. Similar to the experience that I imagine Lori had, but is not actually represented in TWD, I hastily packed my life into a few bags. And just like Lori, among the few belongings I took with me when I left Alberta were the scrapbooks and photo albums that I had created of my life up to that point. This is a moment where both the fantasy world of TWD and my own life demonstrate how the objects that inhabit our lives are mobilized in the creation of our self and meaning in our lives.

Both the character Lori and I placed important meaning on the objects of photo albums. Furthermore, the character Rick also attached specific meaning to the fact that the objects were missing. The Grimes family photo albums are never mentioned again and are presumably lost when Lori and the group make a hasty exit from a safe haven. Interestingly, once I moved to Ottawa I never again filled a photo album or scrapbook with photos. Certainly, some of this can be attributed to the development of digital photography and the storage of photos in the cloud. However, also I see this as a demonstration of how the objects and cultural products that we consume are intertwined 
with the matrix of human relations that come to construct the self. The human relationships that I had invested in the photo albums which made the journey from Alberta to Ottawa were severed and the object and the activity became personally connected to a time, place, and set of relationships that I had left behind. Once in Ottawa I was forming a new matrix of relations and not only did the human subjects in that matrix change but so did the consumer products that I used to retain and memorialize and define that matrix of relations.

Obviously, there is the economic understanding of consumption which is at the heart of our consumer culture. The global economy relies on and operates because of the literal consumption of things by humans. And while this economic motive is in action in the sale and consumption of cultural products like TWD I would like to demonstrate how consumption takes on other meanings at the individual and personal level. This project has been organized around my personal experience as a fan of this series. When I take in the story of TWD I have an emotional reaction to that consumption. The methodology chapter of this project was a specific effort to analyze and consider the way that my individual emotional experience influences the meaning and knowledge that I take from the text. The previous section outlined how consumer goods such as photo albums can be integrated into the matrix of human relations. It is the linking of emotion with consumptive practices that allows these consumed cultural products to be included in an understanding of the matrix of relations. My consumption of TWD is not limited to my economic consumption of this cultural text. I take the story and characters of TWD in when I watch the series or read the comics. The character cannot be in relationship with me in a way that a human matrix of relations is explained by Butler, however, I think that 
cultural products such as a character can still be understood as an aspect of the matrix of relations that is used to construct my sense of self. The character Andrea is the perfect case to consider how the consumption of characters and story can be integrated into the matrix of relations that constitute the self. While there are particular moments in the story where I emotionally identify strongly with Lori, Andrea is the character that I saw as most like myself. In some ways, Andrea came to be the character that I saw as most representing myself in the series. As someone who has an unstable internal sense of self it is significant that I can still identify the features and actions of the characters that I think are representative of what I would do.

Andrea is a woman in the group of survivors that Lori, Carl, and Shane have taken refuge with. Andrea is with the group who rescued Rick from certain death and reunited him with Lori, Carl, and Shane as well as the rest of the group of survivors. After Rick and Lori's reunion, Lori confronts Shane, who at that moment is playing with Carl, about his lie and informs him that she wants no further contact between him and herself or Carl. Nearby, Andrea, Carol and some of the other women in the group are doing laundry by hand in the lake. Andrea makes an explicit, overt observation of the gendered division of labour in the scene, noting that Shane is playing with Carl and that Ed is just standing watching the women as they do the laundry. This is the first time that Andrea observes and comments on the gendered division of labour in the world of the zombie apocalypse, but as will be discussed it is not the only time that she makes such an observation. The women begin to discuss modern comforts, finally Andrea suddenly says that she misses her vibrator and the women chuckle. Then Carol says very quietly that she also misses her vibrator. The group of women doing laundry erupt into loud 
laughter. Ed, Carol's abusive husband, approaches and demands that Carol stop laughing and focus on her work. Andrea confronts Ed and tells him he should do some work. Ed threatens Andrea and the situation escalates until Ed strikes Carol. Shane, likely spurred by his earlier confrontation with Lori, has an immediate and extremely violent reaction to Ed's assault on Carol. Shane beats Ed severely and the group of women who had been working have to stop Shane.

Andrea loses her sister Amy in a sudden attack by a herd of zombies. The badly beaten Ed is also killed. The group manages to fight off the herd of zombies but some are killed and one is bitten but remains alive. The group decides to seek out assistance at the Center for Disease Control (CDC) in Atlanta. While at the CDC the group enjoys some creature comforts and some of the characters are forced to confront their trauma. While browsing the CDC recreational library, Lori is assaulted by Shane when he drunkenly insists that she still has feelings for him. Lori resists the assault, striking Shane and scratching him. As the CDC building begins to lose power, the group is informed that the building will self-destruct in an explosion to kill all of the pathogens contained in the building. The lone scientist encourages the group to remain in the building and end their suffering with the destruction of the building. Two people opt to remain in the building as it self-destructs, a very minor character named Jackie and Andrea. However, Andrea's decision to end her life is not acceptable to her traveling companion, Dale. Dale tries to convince Andrea to leave and when she will not he refuses to leave as well. Not wanting to be responsible for Dale's death Andrea agrees to leave the building with him before it 
self-destructs. The first season ends when the group escapes the CDC just as the building self-destructs with one group member, Jackie remaining behind.

Picking up on Andrea's aborted decision to end her life, the first half of the second season focuses on themes surrounding the value of life in the postapocalyptic world. Some of the further implications of this theme will be discussed a little later in chapter five. The group spends the first half of season two searching for Carol's daughter, Sophia. After Carl is shot, the group takes refuge with the Greene family: Hershel, Maggie and Beth. While Carl is healing, Lori discovers that she is pregnant, leading to Rick confronting her about her relationship with Shane. Upon learning of Lori's pregnancy, Shane confronts her, insisting that the child must be his. Lori denies this, asserting that Rick is the father. A growing conflict between Shane and Hershel comes to a head at the conclusion of the first half of season two and it is discovered that Sophia had been dead the whole time the group was searching for her.

The second half of the second season focuses on the debate about how to deal with a prisoner who belongs to what appears to be a dangerous group of male survivors. The debate centers around issues of due process and guilt by association. Some members of the group believe it is right to keep the prisoner captive. Shane and others believe that it would be best to kill the prisoner rather than risk his escape and return to the dangerous group he represents. Rick is torn between these two decisions, leading to significant conflict with Shane, escalating to the point of physical confrontation between the two. At 
the end of the second season Andrea, is separated from the rest of the group when a herd of zombies attacks the Greene farm.

After she is separated from the main group, Andrea is rescued from zombies by a woman named Michonne. Michonne will be discussed in more detail later in this project. Andrea and Michonne make their way to a community known as Woodbury. Andrea and Michonne have fundamentally different reactions to Woodbury and its leaders. Andrea is exceptionally grateful to their rescuers and trusts the community's leader, a man known as The Governor. Michonne eventually makes the decision to leave Woodbury; however, The Governor sends a group of men to track her down and kill her.

Lori is close to the delivery of her baby, and after months on the road the survivors are desperately looking for shelter. Lori and Rick are not on speaking terms. The group takes shelter in a prison facility. During an instigated zombie, attack Lori goes into labour and dies during an emergency cesarean section. The group goes to extreme measures to provide for the baby, a girl whom big brother Carl names Judith. While out searching for formula and other baby supplies, Glenn and Maggie are captured by one of the men that The Governor has sent after Michonne. Michonne witnesses Glenn and Maggie's capture and retrieves the supplies they had gathered and traces their path back to the prison where Rick and the rest of Andrea's former companions have taken refuge. Andrea seeks out an active role in the protection and leadership of Woodbury just as she had on the Greene farm in the second season. However, The Governor repeatedly rejects her attempts at protection and leadership, suggesting that she offer comfort to the other women and children. Andrea and The Governor begin a sexual relationship before she learns that he sent men to kill Michonne and that he is holding Glenn and Maggie 
hostage. Once Andrea learns of the conflict between The Governor and Rick's group at the prison, she attempts to broker a peace between the two men. When the Governor and Rick do finally meet, both of them explicitly reject Andrea's presence at their negotiation. Andrea is told to wait outside the building while the two men discuss the conflict.

As a viewer I found this storyline extremely frustrating. I think I found this story frustrating especially because I often saw Andrea as something of a surrogate for myself in the story. What is more, I think that there is a fundamental way that I can imagine Andrea's frustration at her exclusion from this decision-making process. I do think it is important to note here that my frustration is not a masochistic experience as some scholars have chosen to characterize the way that female viewers experience the horror genre. There is a power in seeing our own experiences reflected in the cultural texts that we consume. The frustration that Andrea experiences at her exclusion from the peace process is an experience that I am familiar with, that in different ways I have experienced myself. There is a way that the representations of this cathartic frustration is not an experience I am alone in, but one that I share with both the character Andrea and the other female viewers of the series. Some of The Governor's motivations for excluding Andrea from the negotiation with Rick will be discussed later in this project, but for now I will focus on the conclusion of Andrea's story arc. Andrea returns to Woodbury with The Governor after the meeting with Rick. The Governor lies to Andrea about what the outcome of the negotiation was. Eventually Andrea discovers The Governor's true plans and attempts an escape. However, Andrea is captured and restrained in a room with a dying man who, once he dies, returns as a zombie. Andrea fails to kill the zombie before 
it bites her. Michonne and Rick arrive in time to assist Andrea in ending her own life before she can become a zombie.

\subsection{A Woman's Place in the Apocalypse: Lori and Andrea's Fight}

As a means of carefully examining some of the ways that the series relies on a logic of masculinist protection I will focus particularly on two of my favorite episodes of the series: S2E10 "18 Miles Out" and S2E11 "Judge Jury and Executioner." In S2E10, Andrea and Lori have an argument about, among other things, what the proper role of women should be in the zombie apocalypse. Lori argues that Andrea's refusal to help with the established gendered division of labour where women do laundry and cook is a burden on the rest of the women. Furthermore, Lori asserts that Andrea should let the men handle the protection of the group. Andrea in turn argues that Lori's efforts to provide creature comforts and stability are futile if the group is not safe. Both women are critical of the role that the other has chosen to fulfill in the post zombie apocalypse world. Furthermore, Andrea and Lori argue about the rights and ability of people, in this case the youngest Greene sister, Beth, to make decisions about their own life or death. However, Lori and Andrea each in their own way fundamentally fail to live up to the standards of good women demanded by the logic of masculinist protection.

In the world of TWD it is the responsibility of the women to be on guard against the 'bad men' of the apocalyptic world, a responsibility that both Lori and Andrea have failed to fulfill. Lori failed to see Shane as the bad man that he ultimately was when she chose to embark on a sexual relationship with him. Andrea also fails to see Shane as the bad man that he is and has a sexual encounter with him as well. In the third season, 
Andrea again fails to recognize a bad man and has a sexual relationship with the Governor. Both Andrea and Lori fail to recognize the bad men when they encounter them. In an important way, this is further justification of the subordination of women as a class needing to be protected. If women are deemed incapable of identifying good and bad men, then the responsibility to identify good and bad men will fall to their masculine protectors. Andrea, by rejecting the gendered division of labour that Lori advocates, also rejects the protection of the men. Andrea demands to fulfill a protector role herself, a deviance from the standards of good women that Lori finds particularly offensive.

The scene featuring the argument between Lori and Andrea in S2E10 was a particular stand out for me when I watched the series. As a viewer of the series, I often ask myself what I would do in situations such as those faced by the characters in the series. In early discussions with friends about the series much of this conversation focused on the differences between the two central male characters of the series, Rick and Shane. Andrea and Lori's argument presented viewers with the question: which of two female characters behaviour and beliefs about this destabilized world do you as a viewer identify with? However, there are a number of ways that the scene, while it asks viewers to consider this world from the perspective of two of the female characters, reproduces a system of relations that fundamentally subordinates the women of the destabilized world of TWD.

Andrea and Lori are in fundamental disagreement about what role women should play in the world of the zombie apocalypse. Andrea advocates for men and women equally occupying the position of protector and provider while Lori argues that by fulfilling the gendered domestic labor of laundry, cleaning and food preparation the 
women of the group provide stability and are building the parts of a new life. Lori tells Andrea that the men can handle the protection of the group and that the men do not need Andrea's help. Lori is advocating a position that appropriately lines up with the role of women in a world structured by Young's (2003) logic of masculinist protection. Under the logic of masculinist protection, it is the women of the world who pursue the “elevating and decorative arts" that bring deeper meaning to life (Young, 2003, p 4). Andrea's response is that she is guarding the group from danger which is what really matters, not 'fresh mint in the lemonade' (S2E10). We can see in this argument the power that gender based dualities have in shaping the understanding that the characters make of their world. It is significant that Andrea's response to Lori's challenge is to diminish and minimize the work that Lori is advocating. However, this is the very work to which Lori is relegated by the gendered logic. Andrea is complicit in the discursive devaluation of the work of women with her claim that Lori's gendered labour is inherently less valuable than the labour that is deemed male. Andrea discursively subordinates Lori by devaluing her labour.

Lori is also complicit in the devaluing of female labour in the world of TWD. Lori claims that Andrea's work as a protector has no value and can be better accomplished by the men in the group. Both Lori and Andrea discursively reduce the other to one aspect of their being. Lori denies that women can be protectors because they need to provide stability and comfort and Andrea denies that stability and comfort are important things in 
the zombie world. Both women rely on a set of mutually exclusive gender roles that restrict and confine the behavior of individuals in the world of TWD.

My use of a reflexive positioning of the self in the story being consumed is reflected in the online community's discussion of the series as well. In response to episode S2E10 the online community created two polls about the issues addressed in the episode. One poll asked "Who do you side with? Andrea or Lori?" (Who Do You Side with? Andrea or Lori?, 2012). The poll is not very explicit about what precisely it is that the respondent is agreeing or disagreeing with, only referring to "the argument" (Who Do You Side with? Andrea or Lori?, 2012). The argument between Andrea and Lori focused on two issues; the gendered division of labour in the apocalypse and the right of people to choose to opt out of life in the zombie apocalypse. The results of the poll did not offer the community a chance to make a nuanced choice about each of these issues however, the community did discuss those nuances in the discussion that accompanied the poll. User TheILLness refused to pick either Andrea or Lori as the correct party in the argument, arguing instead that "both had good points and both were wrong in their own ways. and both can be like nails on a chalkboard. can we PLEASE get a woman on the show that isnt a pain in the ass?" (TheILLness, 2012). As discussed in the methodology chapter there was a significant amount of dissatisfaction expressed about the female characters among a broad variety of online fan communities. Even in the specific context of this poll, discussion users took the opportunity to express their dislike of the characters: "Lori. Why? As much as I hate Lori, I DESPISE Andrea." (Syphon, 2012). Some respondents were explicit in what aspects of the argument they felt each character had been correct in. Six of the respondents to the discussion of the poll about the argument 
explicitly said they disagreed with Andrea's decision to leave Beth alone while she was suicidal (Sweetsister, et al., 2012).

There was also an explicit discussion of the aspects of Lori and Andrea's argument that focused on the gendered division of labour. I will focus on the comments of two users: Zambi and TheILLness.

Zambi:

I side with Andrea.

Although I did not like her stunt with the suicidal girl, I believe that she was correct in much of what she said during the fight with Lori. She is right. Lori is self centered and takes for granted what she's got. Plus, I did not take kindly to Lori's gender play with Andrea. Although her husband and Shane want to protect her, has the thought occured to her that it is not up to the rest of the males to assume the position of her knight in shining armors while she gets to place the laundry damsel that needs their saving if in distress? Andrea has every right to decide where in the group she chooses to make herself useful. If she'd rather be out hunting and slaying zombies, or standing watch instead of laundry duty, so be it. (Zambi, 2012)

TheILLness:

but if i HAD to pick then id say Andrea. im not a chick but the whole, you should be doing womans work was ridiculous especially coming from a woman. and Andrea doesnt manipulate and nag like Lori. i dont agre with how she handled Beth (yes it Beth's choice but Andrea isnt family and therefore didnt have the right to do what she did), but overall Lori is much more annoying (TheILLness, 2012)

While noting that they do not condone Andrea's decision to leave Beth, Zambi, objected to Lori's accusation that Andrea was not pulling her weight because she was not doing the work that Lori believed the women of the group should be doing. TheILLness also noted that even though they are not "a chick" they still found the argument that anyone "should be doing womans work was rediculous" (TheILLness, 2012). Zambi took issue with what they felt was Lori's sense of entitlement with regards to the protection that she received from the group. Interestingly Zambi does not take issue with Lori's expectation 
of protection from Rick and Shane the two men with whom she had a relationship. Zambi's real issue is with Lori's expectation that the rest of the men in the group should protect her. Zambi does not appear to have much awareness of the way that Lori is restricted to the position of 'protected' by the gendered logic that structures the world of TWD. The logic of masculinist protection that structures the world of TWD which places Lori in the position of being protected, also limits those protected to very limited roles. Young (2003) explains that in a world structured by the logic of masculinist protection, the protected class of women are relegated to the elevating arts. Furthermore, Zambi fails to recognize or acknowledge the equally problematic view of gender that Andrea takes in the argument. Andrea in this argument reinforces Lori's subjugation in this world structured by the logic of masculinist protection. Andrea claims that Lori's labour does nothing to actually help the group and is therefore of no value. Following this discussion about the gendered logic of Lori and Andrea's argument, another user came to Lori's defence. After Lori and Andrea's argument, Lori leaves the farm in a car in an attempt to find Rick, Glenn and Hershel. Lori crashes the car on the road and wakes up in the wrecked car with zombies attempting to get to her. Fibber argues that "what happened on the road made it clear Lori is very tough" (Fibber, 2012). Zambi did acknowledge that Lori effectively handled her situation after the car crash but objected to Lori's actions thereafter:

"THEN she decided it was a good idea to take off into the night on foot heading into a zombie infested town, with one loaded gun of limited bullets. 
Not very bright at all, and she did need the wisdom of a man to talk her away from doing that." (Zambi, 2012).

Zambi, here in the online community, replays one of the themes present in the series' depiction of female characters. Lori's choice to search for Rick is marked as invalid, and Shane, the man, is presented as her wise saviour. Zambi neglects to acknowledge that Lori's wise protector Shane once again lied to Lori to force her to deviate from the course of action she wanted to undertake. Zambi's comments reflect an understanding of Lori's behaviour that is consistent with the logic of masculinist protection that structures the series. Importantly, Zambi's comments demonstrate how those protected in a world structured by the logic of masculinist protection are subjugated by that protection. In Zambi's view Lori's failure lies in her very adherence to the gendered norm of being protected.

The other important theme of S2E10 and S2E11 is the question of how to deal with prisoners in the world of the zombie apocalypse. As seen in S2E10, the fundamental difference between Shane and Rick is that Shane advocated a no questions asked take no prisoners stance and would not hesitate to kill another human who seems like a possible threat to the people Shane loves. For the first three seasons, Rick is more measured than Shane in his approach, wanting to take time to consider and discuss all of the options before coming to a decision. In the case of Randall, the prisoner under consideration in S2E10 and S2E11, Rick thinks the prudent course would be to execute the prisoner; however, unlike Shane, Rick wishes to debate and consider the issue before acting. The online community reflected on this theme with a poll and discussion like that about the argument between Lori and Andrea. The group's decision about how to handle the 
prisoner Randall is addressed in different ways in the discussion of both S2E10 and S2E11. For S2E10, the fan poll question focused specifically on what the group should do with Randall. Respondents had four choices: Kill Him, Take Him In, Abandon Him Somewhere or Keep Him Prisoner (What should be done with Randal? thewalkingdeadforums.com). This formulation of the poll question generated some responses that indicated that the users had put significant thought into their responses. User Syphon outlined a plan of action, even emphasizing the necessity for the group to be kind to their captive:

I choose a middle ground between keeping him prisoner and taking him in. You treat him kindly and don't torture him for information, or anything like that, and just let him hang around. Feed him what you eat, clothe him what you wear, but he isn't exactly a free man to go out and about without being kept an eye on. Almost like a slave--he's the group's property--except without the cruelty. He'll be like on probation, almost, except constantly on watch by a designated member of the group. Keep him away from weapons, but bait him by keeping an unloaded pistol with the designated member of the group watching Randal, to test his trustworthiness. A key part to this is YOU DON'T TREAT HIM LIKE HE'S LESS THAN YOU. He's a human being, too. (Syphon, 2012)

Interestingly Syphon's call for kindness is limited by the threat that Randall represents.

The threat or danger that Randall represents justifies taking a view of him as 'property', as a 'slave'. Once again the motivation to protect results in the dehumanization and denial of another human's agency, in this case the reduction of the prisoner Randall to the position of property or slave.

The poll for S2E11 addressed essentially the same question about Randall however, it reflects the change in Rick's position. By S2E11 Rick has taken the position that the prudent course of action would be to kill the prisoner, although he is ultimately unable to follow through with the plan to execute Randall. In S2E11 Rick and Dale have 
taken opposing positions in this discussion, Rick advocating execution and Dale arguing for mercy. The fan poll for this episode reflects the change in Rick's position and simply asks fans if they side with Rick or Dale (Who Would You Have Sided with, 2012). The responses to this poll demonstrate how the dichotomy of good men and bad men is central to the way that the fans understand this particular moral situation. More than half of the respondents to the poll agreed with Rick that the prudent course of action is to execute their prisoner. The threat that Randall's larger group represents is repeatedly referenced by the users as the justification for their belief that Randall should be executed. Again in this thread the users explicitly emphasize the need for compassion in the way that the group handles Randall. One of the elements of this story thread that most interested me was Lori's response to the debate. Lori and Rick have a direct discussion of the issue as Rick is attempting to arrange an effective execution for Randall. In the discussion, Rick acknowledges that prior to the zombie apocalypse Lori had been explicitly opposed to the death penalty. However, Lori responds by saying that she agrees with what Rick thinks is best, a conversation that is repeated in a very similar manner in the third season when discussing the fate of the prisoners who were already in the prison when the group arrived. This brief conversation between Rick and Lori was not addressed at all in the discussion that the online community had about this issue. However, to me this was a vitally important part of this storyline, as Lori was explicitly surrendering her agency in this matter to Rick. Lori was manifesting exactly the kind of subjugation that is 
required and expected of her by the logic of masculinist protection that structures the story.

\subsection{How to be worthy of Protection}

Since its premier in 2010, The Walking Dead has been incredibly popular. The series has repeatedly surpassed NFL Sunday Night Football in the all important key advertising demographic, adults 18-49 (Hibberd, 2016). Young (2003) argues that gender is a tool not to explain the existence of the current security state, but rather that gender should be used as a tool for interpreting and understanding the way that security state has taken hold, and so too can it be applied and used the same way in an analysis of The Walking Dead. An analysis of the gender relations in the series The Walking Dead, like Young's analysis of the contemporary security state, is illustrative of the way that established gender norms and tropes have popular appeal in times of or, as in this case, stories of great ambiguity or strife. The world of The Walking Dead is one ruled by a monster that is fundamentally destabilizing. The zombie, as already discussed, throws what appears to be the most essential of apparent binary divisions, that of life and death, into flux, thereby calling all of society and social life itself into question (Jones, 2013). Much like Young outlines in her discussion of the contemporary security state, it makes sense that in response to that state of absolute instability and flux, the series relies on a logic which rests so heavily on traditional gender roles and tropes. The reliance on established traditional gender roles and tropes offers a feeling of security and safety in what is a fundamentally destabilized world. There is a sense of safety created for both the viewer and for the survivors of the apocalypse in the retreat to these seemingly 
stabilizing, apparently natural gender roles that are mandated by the logic of masculinist protection.

There is a duality at the center of the logic of masculinist protection that is also at the heart of the story of The Walking Dead; that is the duality of good men and bad men. The good men of The Walking Dead are the story's heroes, Rick and Daryl. These figures are the dominant hegemonic males of the series. There are other good men in the series, such as Glenn, Hershel and Dale. These characters occupy subordinate masculine positions, but they still have a role to play in this imagined society structured by the logic of masculinist protection. For example, Glenn as a Korean American man occupies a subordinate masculine position in relation to the white hegemonic masculine figures of Rick, Shane and Daryl. However, Glenn's status as a good man is confirmed and supported by his relationship with two women, Lori in his roles as protector and provider and in the case of Maggie through their sexual relationship. The bad men of TWD are often a faceless and unseen enemy lurking on the edges of the story, only seen in bits and pieces. As explained in the previous section of this chapter one member of such a group, Randall, is captured by the group of survivors. Daryl, one of the dominant masculine figures, interrogates and learns just how dangerous this group is. Even though he is one of the good men, Daryl explicitly uses this language of ownership to explain to the group the seriousness of the situation. Daryl explains that if our group encounters this group of bad men, all of the good men will be dead and 'our women will wish they were'. Daryl accomplishes two things with this statement: he claims the women of the group as 'our women' or as belonging to the good men of Rick's group; but he also formulates the 
raped woman's life as a life not worth living. Daryl asserts that death would be better for the women than to be raped.

Fear is the primary source of tension in TWD. Initially in the first season of the series the source of fear was the zombies themselves. Ahmed (2004) argues that fear is often generated by anxiety about the loss of that which is loved. When the object of fear approaches, there is a turning away from that which is feared to that which is loved in an effort to create a sense of enduring security (Ahmed, 2004). Furthermore, Ahmed argues that fear is productive of not only distinctions between bodies but also creates boundaries around some bodies when they are identified as frightening. In the case of TWD that which is loved is the group of survivors; it is fear for the survival of the group that motivates the actions of the characters in the series. The fearful object is initially the zombie. While the zombies remain fearsome, a more menacing source of fear emerges, the bad men of the world. The danger represented by the bad men of the zombie apocalypse works to construct the bodies of the female characters as male possessions to be protected and defended. And as Young (2003) explains, to be relegated to the position of the protected is to be subordinate. Furthermore, the construction of women as vulnerable and fearful restricts the movements of women in the world; women must be constantly on guard for danger (Ahmed, 2004).

\subsection{Conclusions:}

The storylines of Lori and Andrea demonstrate how the world of TWD is structured by a logic of masculinist protection. This logic creates a subordinate female status or identity for the female characters. Each of the female characters challenges these 
proscriptions in various ways, each experiencing their own set of consequences. While Carol appears to be a female character who is somewhat challenging to the logic of masculinist protection, there are still limits to what is acceptable behaviour from her. Furthermore Carol is never able to develop an integrated identity that embraces her roles as mother and as protector. While the story told by TWD is dramatic, it is reflective of some of the ways that women, including myself, come to understand who they are in our culture. I will discuss how the post-apocalyptic feminine self created for the characters Lori and Andrea in the world of TWD limits these female characters to roles that support and serve to facilitate the character development of the male characters in the show. 


\section{Chapter: You Know You Left the Fat Chick in Charge of the Food}

\section{Right?}

\subsection{Introduction}

Now I would like to do a more in-depth analysis of some of the discursive and symbolic ways that the story of the TWD constructs its female characters. I will demonstrate how the symbolic meaning of the female characters and their story arc is infected with the logic of masculinist protection with its restrictive and mutually exclusive gender roles. This chapter will expand on some of the ways that the structuring logic of masculinist protection is present in the way that members of one online community understands and interprets the story arcs of the female characters in the series. As discussed in the methodology section of this project, one of the most significant challenges has been limiting and defining the scope of this project. For that reason I once again draw attention to the limits, selectiveness and incompleteness of the data that I am drawing on. I am not attempting to create a representative picture of this particular online community as a whole. I am considering a limited number of conversations about some specific events and characters that were meaningful to me. I believe this is important because this is the way that we really live our lives; we choose to consume things that mean something to us. I do not see my task as to describe the entire culture of the online community being discussed here; I am describing my own experience of that culture. I will consider the way that TWD symbolically constructs women as boundary figures between life and death. I will demonstrate how the women of TWD are symbolically constructed in ways reminiscent of the very monsters that haunt their world, zombies. I 
will demonstrate how this zombie status is manifested both physically and discursively for the female characters of the series. I will then consider some of the ways that I have applied this discursive and symbolic zombie status to my understanding of my sense of self. I will then consider some of the implications of the symbolic representation of women in the world of TWD. I will discuss how some women become symbolically constructed as not worthy of life when they fail to meet the requirements put forth by a culture structured by a logic of masculinist protection. Finally I will consider an online fan conversation about a very minor character named Olivia. I will then explore some of the ways that this fan conversation about the character Olivia are reflective of some of my own experiences of discursive and symbolic devaluation.

\subsection{Matters of Representation: What is the Symbolic Meaning of a Woman}

Not surprisingly to me, I as a woman particularly identified with the women of the series most of all. I was surprised at how much I emotionally identified with the characters; how quickly I imagined myself and my reactions in these situations. By the time the second season finished, I was fully invested in the series. In the second season, Lori discovers that she is pregnant. This was a realization that I found particularly terrifying and poignant. Lori and all the women of The Walking Dead, if they choose to engage in any kind of sexual relationship, run the risk of pregnancy in a post apocalyptic world, which is, in other words, a world without modern medicine. Without the advantages of modern medicine, women in the post zombie apocalypse world have less access to birth control, maternal, prenatal and infant health care. In their Zombie Manifesto, Lauro and Embry propose a number of real life zombies, one of which is the 
mother with puerperal fever. Puerperal fever is caused by the introduction of bacteria into the reproductive tract of a woman who has recently given birth (Lauro and Embry, 2008). In the past this bacteria was introduced by doctors due to a lack of adequate hygiene, which Lauro and Embry note raises some commonalities between the doctor and the voodoo priest who created zombies in Haiti. However, Puerperal fever can also result from natural causes such as an incomplete miscarriage or incomplete expulsion of the placenta following childbirth (Jessica's Trust, n.d.). Just like the fundamentally destabilizing zombie, the body of the woman with puerperal fever breaks down the binary barrier between life and death; that which gives life becomes infected and corrupted by death (Lauro and Embry, 2008). Lauro and Embry (2008) suggest that the female body more generally is often characterized as a border between life and death. England (2006) asserts that in popular culture the monstrous is often symbolically linked with the female reproductive body but that feminist scholarship has often overlooked this formulation of the female body in favour of views of women as victims. England argues that female bodies' ability to reproduce life fundamentally "confuse bodily boundaries" (England, 2006, p. 356). Like this real life zombie proposed by Lauro and Embry, and like the 'monstrous woman' described by England (2006, pg. 356), Lori's pregnant body becomes a boundary between life and death. In Lori's case we learn that she had to have Carl through caesarean section and will therefore likely need another to deliver again. In the end this pregnancy did lead to Lori's death.

The blurring of life and death created by Lori's pregnant body is not limited to Lori herself. Even Lori's need to confirm that she is pregnant puts other people, Glenn and Maggie, in danger. While still on the Greene farm, Lori asks Glenn to find her a 
home pregnancy test at a pharmacy. Going into formerly populated areas looking for supplies is one of Glenn's specialties; however, it is also one of the most dangerous tasks in the world of The Walking Dead. Thus for Lori to confirm that she is pregnant, she needs Glenn to risk death; already this potential new life could lead to Glenn's death. Glenn and Maggie make an excursion to the town nearest the Greene family farm in search of things that the group needs, including Lori's pregnancy test. After Lori has confirmed that she is in fact pregnant she makes a second request of Glenn that he return to the pharmacy; this time she asks Glenn to find emergency contraception or the morning after pill in the hopes that she can terminate her pregnancy in this way. On Glenn and Maggie's second trip to the pharmacy for Lori, Maggie is attacked by a zombie and nearly dies. Upon their return to the Greene farm, Maggie confronts Lori for sending Glenn and Maggie to risk their lives to get the things that Lori needs, including what Maggie calls abortion pills.

\subsection{Zombie Me}

As an autoethnographic project it is necessary that I discuss some of the reasons that Lori's story arc and particularly her pregnancy were very emotionally compelling for me. I was first diagnosed with a mental illness by a family physician in 2003; it was not until 2009 that I began seeing a trained mental health professional, a psychiatrist. My diagnosis has shifted and changed over the years as the therapeutic relationship has developed. With the care of a properly trained mental health professional, I have been able to achieve a much more accurate and fulsome diagnosis of my mental illness along with appropriate adjustments in medication and approaches to therapy. Appropriate 
diagnosis and treatment of my mental illness by a psychiatrist has been instrumental in the ongoing project of my mental wellness. Mental illness is not a passing or temporary condition for me. I live my life with mental illness and the maintenance of good mental health is among the top priorities in my life.

The emotional resonance that I feel with Lori's story is rooted in my own personal fears of pregnancy. I have discussed prospects of my own pregnancy extensively with my psychiatrist. Even with the benefits of modern medicine, pregnancy and childbirth have always held a particular horror for me. My emotional response to Lori's story was particularly powerful because of the added sense of horror I had at the prospect of a pregnancy without medical care. However, beyond the fear of the physical realities of pregnancy, I am also faced with the prospect of postpartum depression. Because I am already predisposed to depression, I am also predisposed to postpartum depression. However, I am fortunate that I have some mitigating factors as well. Because I have an existing relationship with a psychiatrist who provides me with regular support, any postpartum depression would be rapidly and effectively identified. Furthermore, I have an extensive history of individual and group therapy to draw on for support. However, it is the risk of the potential to slip into depression that makes pregnancy so frightening for me. As I have outlined, the female reproductive body is symbolically linked to an unstable boundary between life and death. These themes and symbols are present in Lori's story arc in TWD. Lauro and Embry (2008) even use the body of the postpartum 
woman as a potential real life zombie. My increased risk of postpartum depression presents me with additional horrors: the horror of becoming a depressed/zombie me.

I think it is important to be honest and frank at this point. Depression is not a state or condition to be taken lightly. A state of depression can be a state of risk and danger. In periods of emotional crisis, be that in the form of depression or profound anxiety, I have experienced periods of suicidal ideation. I refer to the state of depression as a zombified state not to make light of the condition. For me the zombie and my careful critical academic consideration of the zombie has been a powerful tool for understanding and coming to terms with my own struggles with mental illness. Furthermore, my apprehensions about the potential for postpartum depression are an important part of why Lori's story arc was so compelling to me.

\subsection{Suicide Girls: Female Agency in the Zombie Apocalypse}

The question of whether life is worth living in the zombie apocalypse is one of the central questions of The Walking Dead, and a masculine-feminine divide is often at the center of this debate. In the first episode of the second season, Andrea has an argument with her closest male companion Dale. In the first season finale Dale had forced Andrea to leave the CDC building in Atlanta before it self-destructed. Andrea had lost her younger sister to the zombies early in season one and had been struggling with her grief. As the second season begins, Andrea realizes that Dale has confiscated the gun given to her by her father and she confronts him, demanding to have it back. Dale asserts that he cannot trust Andrea with the weapon as he is afraid she will hurt herself with it. Andrea chastises Dale for once again taking her choice away and informs him that he did not 
suddenly make her realize she wanted to live, she only wanted to avoid being responsible for Dale's death. Andrea asks how Dale expected her to feel about this and Dale proclaims that he expected her gratitude. Young (2003) notes that the logic of masculinist protection requires not only that women not resist the domination of those who protect them but also that women are grateful for their protection. Andrea rejects her subordinate position and demands to be an active member of those protecting the group. Furthermore, Andrea explicitly rejects Dale's demand for her gratitude. Andrea points out that, by taking her gun Dale is again taking away Andrea's choices just as he did by refusing to leave the CDC. Dale is denying Andrea's right to decide how she will act or behave or proceed with her existence. Andrea's belief that the decision to live on in the world of the zombie apocalypse must be made by each individual will be addressed again later in this chapter.

While waiting for the equipment necessary for Hershel to perform life saving surgery, Lori and Rick discuss if it might be best for Carl to die and for his suffering to end rather than for him to go on living in the horrible world of the zombie apocalypse. Lori is the parent arguing that it might be better for her son to die than to live on in the world of the zombie apocalypse, while Rick fulfills his masculine role as wise protector of his son and argues the other side of this ethical debate, asserting that Carl is focused on the beauty that still exists in the world rather than the horror. So Lori, the mother, advocates for the death of her child, which is something that seems to be at odds with her status as a mother. Meanwhile, Rick retains his role as the wise guiding protector. This is 
a symbolic initiation of the monstrous, death-bringing femininity captured later in the story by Lori's pregnancy.

Beth Greene, youngest daughter of the Greene family, in a state of distress attempts to steal a weapon, a knife with which to end her life. Discovering the missing knife, Lori confronts Beth and demands the knife back. Beth surrenders the blade and Lori goes to find Beth's family. Andrea and Lori have an argument, which was discussed in detail in the previous chapter, about the appropriate course of action in response to Beth's behaviour. Andrea, believing that Beth had the right to decide her own future, left the explicitly suicidal Beth alone, allowing Beth to attempt suicide. Beth's suicide attempt is made at a time when her father Hershel is absent, having gone missing because of his own emotional turmoil. Narratively this story is similar to the conversations between Rick and Lori when Carl was shot, as well as Andrea and Dale's exchange following the events at the CDC. Because Beth's suicide attempt happened during her father's absence, it could be concluded by the viewer that, had her wise and protecting father Hershel been present, she may not have been driven to such drastic action. Furthermore, it was a woman, Andrea, who left Beth alone explicitly giving Beth the opportunity to end her life. Both Lori and Maggie, Beth's sister, reinforce Hershel's position as protector when they immediately seek him out after Beth's suicide attempt. Upon his return to the farm, Hershel stitches Beth's wounds and is seen tenderly singing to her as she smiles at him. In all three of these cases, the women are opting for death 
over life and in all three cases a man is the counterpoint, stating that life is the better choice, further establishing the feminine as a monstrous marker of both life and death.

I would like to draw attention to what I see as a significant resonance between my experience as someone who is mentally ill and some of the ways that the agency of the female characters in TWD is undermined. As explained, receiving adequate and qualified treatment for my mental health has been a long process. Similarly, the process of identifying effective pharmacological and therapeutic practices has been a long process. However, the work of and trial and error that goes into this process is fundamentally private. While I am very open and honest about the fact that I have a mental illness, I don't necessarily share information about my treatment or diagnosis with everyone. I have on multiple occasions had encounters with people where they express their personal opinions about what kind of treatment and even what kinds of diagnosis are appropriate. Sometimes the conversations are innocuous and easily dismissed. But I have experienced this with people who are in positions of authority over me. Someone who was a direct supervisor, and not a medical professional, explicitly inquired about my pharmaceutical regimens. I offered the information and was promptly informed that I should not be taking medications and I needed to get off them as soon as possible. Similarly, I was informed by a medical professional when at a consultation about something unrelated to my mental health, that if I followed this doctor's directives I would no longer need to be medicated because my mental illness would go away. When this kind of interaction occurs, I assert that my agency is being undermined in a way that is similar to the way that the female characters in TWD have their agency undermined. I argue that in both of these cases there is an attempt to discursively remove me from the decision making about 
the treatment of my mental illness. These individuals, with no special training in the treatment of mental health and with no therapeutic history with me, believed that they were appropriately positioned to know what was best for me. I see an important emotional resonance between the way that I feel at moments such as these and the way

that some of the female characters in the series have their own agency limited by the male characters. Decisions about how to spend your time, how to manage your health and even decisions about life and death are at the very center of what it means to have personal agency. The female characters in the series have their decisions about how to live their lives repeatedly undermined by the male characters, just as I have had my own decisions about my mental health care undermined by unqualified men in my own life.

\subsection{Violence and Sexuality Unscene: Michonne Sanitized}

Explicit uses of different levels of meaning is a common trope in popular entertainment. Many television series have such hidden messages and patterns waiting for the inquisitive fan. The many television and film works of J.J. Abrams feature common references like the fictional commercial airline Oceanic which appears in the tv series Lost as well as Fringe. In the animated workplace comedy series Futurama, in the background you can see what is meant to be an alien language. This alien language is actually a cypher that dedicated fans can solve to reveal hidden jokes all through the series. These are examples of something that fan communities refer to as Easter eggs, hidden surprises for dedicated fans to identify. In the case of TWD some of the Easter eggs are references to particular moments in the comic book series. The specifics of one 
particular Easter egg in the series TWD deserves particular consideration in the context of this project.

In the third season of TWD a significant villain from the comic books is introduced: The Governor is the leader of a group of survivors in a town called Woodbury. I found The Governor to be a particularly horrifying villain when I read the comic books and I was anxious about his arrival in the television series. I was particularly anxious about how Michonne's experiences with The Governor would be translated from the comic book to the television series. In the comic book Michonne is held prisoner, and tortured and raped by The Governor. After Michonne manages to escape she then inflicts extreme revenge on The Governor including mutilation and sexual assault. These acts of violence are never represented directly in the television series; nevertheless, my knowledge of the storyline from the comic books did influence the television viewing experience, regardless of how the plot played out in the television series. The Governor as depicted in the television series is somewhat less violent and sadistic than his comic book counterpart and does not engage in his comic book counterpart's most violent behaviours. In the television series, The Governor does hold Maggie and Glenn hostage and forces Maggie to strip from the waist up and forces her into a vulnerable position but does not rape her.

While not depicted, the sexual violence that Michonne experiences in the comic series is referenced directly with a scene in the television series. In the comic books the Governor restrains Michonne in a very specific way when he holds her captive. In the television series, the Governor is depicted constructing this restraint. Furthermore, while constructing the restraint The Governor is seen positioned in a way reminiscent of the 
positioning of Michonne in the comic book. To a viewer who had never read the comic books this scene was just an establishing shot: a fly on the wall look at the preparations of the villain. But to the viewer such as myself who has read the comic book series the image has a different meaning because it reminds the comic book reading viewer of the sexual violence that The Governor inflicts upon Michonne. I find this Easter egg reference to this sexual violence particularly troubling in light of Butler's (1990) discussion of the relationship between reality, fantasy and censorship (discussed previously in the theory chapter). This clear and obvious reference to, but not representation of, sexual violence is troubling because of the way that Butler conceptualizes prohibition or censorship as an eroticizing force. While my data collection process did not take place during the airing of the season three story lines, during my exploration of the online communities I encountered numerous threads that were centered on discussions of things that might not be translated from the comics to the television series. I decided to capture these threads because of the powerful way that they reminded me of this story line. Though I captured some of these threads, I was frankly unable to bring myself to dive deep into the content of these threads. I found the mere existence of these threads troubling, and had a real sense of dread at the prospect of any kind of gleeful discussion of this sexual violence. The existence of the threads is enough to demonstrate that some users of these fan discussions are similarly aware of the hidden meaning in the depiction of The Governor constructing the restraints used to hold Michonne captive.

Another significant element of Michonne's comic book character that is excluded from her character in the television series is comic book-Michonne's sexual assertiveness 
with some of the male characters in the series. Michonne actively pursues a sexual relationship with more than one male character in the comic series; in the television series, this aspect of the comic book character is not present. Importantly, in the sixth season of the television series Rick and Michonne begin a romantic relationship. In the comic books Rick and Michonne never have a romantic relationship (Rick's love interest during similar plot points in the comic books is Andrea). The exclusion of both comic book Michonne's overt sexuality and the sexual violence she experiences is important in light of her eventual relationship with the main protagonist of the series. In a world ruled by a logic of masculinist protection where women must be constantly on the lookout for bad men, this change to Michonne's character makes her a more acceptable companion for Rick. As I explained earlier, the series explicitly marks the life of a raped woman as a life not worth living. Based on that logic, the comic book version of Michonne would be better off dead after she is raped by The Governor. Furthermore, as I outlined, both Lori and Andrea failed to recognize the bad men of the world of TWD and engaged in sexual relationships with men who turned out to be bad. The exclusion of comic book Michonne's active pursuit of sexual encounters prevents her from failing to live up to (as both Lori and Andrea do) the standards set for her in this world structured by the logic of masculinist protection. This sexual and violent sanitization of the comic book character Michonne allows her to be an acceptable companion for the hero of the series because it brings her character in line with the requirements of the logic of masculinist protection. I would like to place a limit on my autoethnographic analysis of this particular storyline for two reasons. First, I am not a person of colour and I think that there is significant value that could be added through the further autoethnographic analysis of 
Michonne by a person of colour. Second, while my emotional response to the violence that Michonne experiences in the comic book series was powerful, it was not the reaction of someone who has experienced major sexual violence. An autoethographic researcher who is a woman of colour and/or survivor of sexual violence would offer an important perspective on this story that I am unable to provide.

\subsection{Olivia: You Know You Left the Fat Chick in Charge of the Food Right?}

The final character from The Walking Dead that I would like to discuss is a very minor character named Olivia. Olivia is a resident of the Alexandria safe zone and had been very sheltered during the events of the zombie apocalypse. Olivia is responsible for managing Alexandria's inventory of food, alcohol, tobacco and weapons. In both the television series and the comic book, Olivia is depicted as an overweight white woman. I am also an overweight white woman and therefore I felt a particular resonance with Olivia. As explained earlier, I was able to personally identify with the stories of both Lori and Andrea in significant ways because I was able to see elements of my life and self reflected in those characters. The characters Michonne (a woman of colour) and Carol (a survivor of domestic violence) became more central to the series after the deaths of Lori and Andrea. However, I did not feel the same resonance with their stories because I did not feel as much connection between my experience and their stories. Olivia did resonate with me because she was literally the first woman in the series that I could say kind of looked like me. Over the course of Olivia's story line, I found myself extremely anxious about how her story would unfold. As a reader of the comic books I am aware of how the story plays out in that format. However, the television series is not always exactly like the 
comic book series. At times when I was expecting an act of violence or a memorable death was expected based on the comic book series, I became anxious about whether Olivia's story would change and she would become the victim of one of these acts of violence.

I would now like to discuss a fan thread that is explicitly discussing the character Olivia. On this particular fan site each character has their own dedicated thread that the fans use to discuss the character. The Olivia thread begins with a GIF of two men dancing with the words 'big bootie bitches' flashing over it. The first five comments in the Olivia thread all made either explicit or implicit reference to the size of Olivia's body. (Olivia, 2015) It is not until the sixth comment that someone (WalkingBuckeye, 2015) explicitly asks that the discussion focus on the character and the story rather than just be a series of fat jokes. WalkingBuckeye is promptly told that they need to 'settle' basically telling the person to just shut up. Another commenter asks if the WalkingBuckeye has "seen this forum" presumably indicating that the kindness the comment asked for was unlikely or atypical of the forum. The discussion goes on to further justify the focus on Olivia's weight by pointing out that the character is fat in both the comic book series and the television series.

Some commenters then turn the discussion to how they imagine some villains from a previous story line would react to Olivia. The villains from this other disconnected story line were a group of people who had become cannibals after the zombie apocalypse and the fat jokes transition to jokes about how much the cannibals would have loved Olivia because of the size of her body. WalkingBuckeye returns again asserting that their experience in this forum had not been this cruel in the past. WalkingBuckeye goes on to 
list the name of the actress who plays Olivia, "a factoid which usually appears in the first post about a new character" (WalkingBuckeye, 2015). WalkingBuckeye expresses some frustration and even tells some of the other forum users to ' ${ }^{* *} \mathrm{k}$ off' but in a subsequent post apologizes for the profanity and admits to feeling bad for the actress because this discussion has not been about the character at all but simply about making fun of her body.

One of the commenters who had been a part of the mocking discussion then asserts that his focus on Olivia's body is not insulting because he calls her a "sexy beast" and "like.. Legit 10/10 would bang" (TGO, 2015). This is a particularly telling comment in this thread and one that it is important to link to the overall structure of the world of TWD as one structured by the logic of masculinist protection. TGO is asserting that Olivia has value explicitly because she is aesthetically and sexually appealing to his eye. Furthermore, TGO believes that his approval of the shape of Olivia means that his mockery of her shape is ok. At this point WalkingBuckeye gets some assistance from another user; CheesyBirdMess points out that the same users who are currently making fun of Olivia's body are the same users who vigorously defend other characters when issues of race, disability of sexuality are the subject of mockery (CheesyBirdMess, 2015). TGO defends his mockery of Olivia by pointing out that weight is a part of her character; furthermore, TGO argues that weight unlike race, disability or sexuality are not things that you are "born with or stuck with". The thread continues for some time however at 
this point I would like to shift to some of the ways that Olivia and this thread have particular resonance with my life.

\subsection{The Value of My Life}

The labeling of some lives as not worth living is an important issue to spend some time here discussing. I have personally had confrontations with moments where the value of my life is questioned. In one of the courses that I completed for my graduate program, a professor offered bonus points to any students that they saw working out at the campus fitness facilities. In this same class with this same professor there was a discussion of the discourse around the issue of obesity. The professor claimed that it wasn't right that he, as someone who took care of himself, should have to pay for the medical costs of people who do not take care of themselves and are therefore obese. Much of the contemporary discussion of obesity has shifted to an environmental account of the issue. One student in my class even objected to the professor's characterization of people who are obese as 'not taking care of themselves' asserting that there are a number of complex social and economic factors at play in obesity. The environmental account of obesity argues that contemporary sociocultural and economic environment predisposes some groups, particularly racialized and low income individuals to obesity (Kirkland, 2011). In the shift to an environmental account of obesity, there is an apparent rejection of the formerly common moralistic attitudes that a large body implies moral weakness and lack of selfcontrol. Kirkland notes that the environmental account of obesity has been widely accepted by feminists and her own critiques of it have been dismissed as classist or racist. However, Kirkland argues that the imposition of regulations seeking to mitigate the environmental causes of obesity are in reality "intrusive, moralizing and punitive" to 
those they claim to help (2011, p. 464). Kirkland explains how the environmental account of obesity still implies that obesity is the result of a moral failing and lack of personal responsibility by those groups most likely to be obese. Social change that addresses the issues that create the environmental causes of obesity focus on providing the consumer with more knowledge and more choice. The implication of course is that once more choice and more knowledge is available the at-risk consumer will then make so called 'responsible' choices. Kirkland argues that the environmental account of obesity still relies on the belief that fat people have been duped by the evils of consumer culture while those who are thin have achieved that because of their own responsible choices. The fat body is assumed to be the body without knowledge, responsibility, or self-control while the virtues of responsibility, self-control and appropriate consumption are attached to the thin body.

The experience of having a professor discursively construct my own body as deviant and not worthy of social support in the form of health care was a profoundly shaming experience for me. I was the only significantly overweight person in the room when this discussion took place and it felt like instantly every set of eyes in the room of thirty students shifted to me. It was a conversation about bodies like mine that took place in front of me with no regard or concern for the implications that it had for the value of my life. According to this professor, my life was not worth the investments that our tax dollars make in our public healthcare system. As a person who makes extensive use of our public healthcare system in the management of mental illness, this relegates me to a very precarious position should the views of this professor come to influence public policy. Ahmed describes shame as an "intense and painful sensation that is bound up 
with how the self feels about itself" (2004, p. 103). Shame is an act of negation, a failure of the self to appropriately be the self that the social world expects and demands (Ahmed, 2004). Furthermore, shame is fundamentally social; it is something that is "experienced before another" (Ahmed, 2004, p. 103). Even my own sense that the eyes of the class turned to me in the moments of this conversation is a demonstration of the way that shame, while generated by the social interactions of the moment, is one that was turned back entirely upon myself. Ahmed explains that shame is a moment of exposure and visibility of the flaws of the self. The sudden visibility of the faults or flaws in ourselves then leads to an attempt to conceal and turn away from those who are viewing the flaw. However, importantly Ahmed notes that the turn away from others cannot be a turn into the self because in the moment of shame there is a negation of that self, leaving the one shamed with nowhere to turn, resulting in an internalization of that negation of the self. This is exactly how I felt in that moment: I wanted to be hidden from view, to be invisible, to not be seen to not be. As a consequence of this I was silent for the remainder of that week's classes. I had been shamed publicly in front of my cohort and I carried that shame with me to each class for the remainder of the week, not contributing to discussions and hoping that no professor would call on me for anything.

\section{Chapter: Conclusion}

I am terrified to write a conclusion for this project. In the finishing of things there is a sense of closing, ending or finality that seems somehow at odds with some of the primary assertions at the heart of this project. I have attempted to create an understanding 
of both the self and culture as ongoing performative acts of belonging and connection between humans. How is the conclusion of a discussion of something ongoing to be written? More importantly, how do I as someone with an unstable sense of self bring to a conclusion a project that has so enriched my own understanding of myself? Over the course of four years, the project of being a graduate student has been the foundation upon which I have built my sense of self upon.

Over the course of my time as a graduate student I faced two major crises in my sense of self, crises that I have tried to mobilize in the understandings developed in this project. I have attempted to expand the Butler's (2015) conceptualization of the self as a matrix of relations to include our consumptive practices. The cultural products and goods that we consume do not exist independent of the human subjects who consume them. My consumption of either consumer goods or cultural products brings me into relations with both our consumer culture and with the other consumers of those products. I have also demonstrated some of the ways that consumer products, not just cultural products, are also integrated into our understanding of ourselves. Importantly, one of the crises that I faced while working through this project involved a fire destroying my home. This loss of my belongings added and intensified my understanding of the way that the things that fill our lives come to be a part of the matrix that is the source of our sense of self. As Cronin (2000) explains, women have a complicated relationship with consumer culture. Cronin, explains that the ability of women to achieve individuality and identity through consumptive practices is problematic because consumer capitalism constructs women as both consumers and dupes or tools of the capitalist system. The fire that destroyed my home brought much of the way that these issues affect my life into focus. There is a 
significant difference in the look of my home now compared to before the fire. When I moved to Ottawa with my partner I was very young. I was not making much money, working mostly at minimum wage jobs while I was a student. I did not feel that I had much authority to dictate how our income was spent on furnishing our home. However, after the fire it was I who used the insurance funds to replace our belongings. I did all the shopping for furniture, dishes, linens, window coverings and decorations. My partner helped with selecting our bed and picked out our television. I did all of the decorating in our new home myself and in a profound way I can see myself in my home in a way that I did not before the fire. Following the fire, I had a dream about my burned out home; in this dream I broke into the burned out building to try to retrieve my houseplants. Plants and light are at the center of the home that I created after the fire. I believe that both my dream following the fire and the importance (and sheer volume) of my new house plants clearly indicates that these objects occupy an important position in my life. They are inanimate objects; I do not have a relationship with plants in the way that I have relationships with other people, but these objects still come to occupy an important place in my understanding of myself and my home.

An issue that I addressed early in this project is my own relationship to the events of 9/11 and the war on terror. As I explained, these events directly impacted my own life and importantly this project has increased my understanding of those events. The war on terror was sold to the world in part as a war to liberate women. However, as Pham (2011) explains, the discourse surounding the War on Terror contained a powerful conflation of consumerism and freedom following 9/11. Nguyen (2011) outlines the efforts of the fashion and beauty industry to foster western ideals of beauty in Afghanistan following 
the events of the War on Terror. Nguyen explains that the industry presented these efforts as altruistic and liberating however, they also function to develop a new market for the products that the beauty industry produces. The development of consumer economies in the developing world is an imperative for corporations who produce consumer products and yet these endeavors by the corporations were sold to the public as acts of liberation. Furthermore, while Butler (2009) doesn't explicitly state this, I think consumerism is a fundamental part of what marks the west as distinctly modern and different from both Islam and the rest of the developing world. In consumer culture, what we consume is what defines us and this is a distinct development from the time when one's relationship to the church or other cultural institutions were the defining feature of the person. However, the Muslim immigrant is defined by their status as Muslim and by their deviant consumption of different fashions and foods. Butler explains that the supposedly defective nature of the Muslim is extended to the family and powerful reactions to the structural inequalities that disadvantage immigrant communities are conceptualized as failures of paternalistic authority. Furthermore, as Butler explains the anti-racist Paris riots of 2005 which attacked property rather than people were still conceptualized as acts of violence. The conceptualization of vandalism as violence or violence against an object seems only possible in a consumer culture where the products and objects consumed come to represent and identify the person.

Young (2003) does not explicitly discuss economics in her discussion of the logic of masculinist protection. Young explains that the logic of masculinist protection constructs the west as the protector and liberator of citizens oppressed by dictatorial regimes. However, Young neglects to note that this protection only extends as far as it 
furthers the economic interests of the protector state. Young argues that the logic of masculinist protection justifies the invasion of Afghanistan as an act of protection for the women of Afghanistan. However, by extension masculine protection would dictate that the same actions be taken against states such as Saudi Arabia which has equally repressive attitudes towards women. However, the west has economic interest in the oil reserves of a friendly Saudi state and therefore it is of little economic benefit for the west to protect the women of Saudi Arabia.

I have often thought that I could never do the work that my partner does because of my own ethical concerns about the role of the security state in the disenfranchisement of racialized population among other things. However, I do wonder how much freedom employees of the military industrial complex have to exercise their ethical understanding of their work. Particularly in the case of Canada, the economic remuneration, job security and benefits of working in for the governmental defence apparatus distinctly restrict the ability to even consider leaving that industry. My own ethical concerns about James' work are not reflected in his own feelings about his work however, if the financial benefits of the work were not as generous I wonder if his feelings would be different. So the economics of the war on terror extend not only to the interests of nation states or corporations but also the fundamental level of the individual and their own ability to exercise their moral and ethical choice.

Another important theme to address when considering the relationship between capitalism, women and the War on Terror is the male gaze. The very invisibility of the women of Afghanistan by virtue of their restriction to the Burka was what rendered them oppressed and in need of western rescue (Nguyen, 2011). The women of the Kabul 
beauty school were liberated by being made visible. Furthermore, I found it striking that "in this schema of intelligibility the uncovering of a woman's face, through the efforts of others, returns her to humanity" (Nguyen, 2011, p. 371). I think this attachment of freedom and humanity to the visibility of these women is a fundamental reflection of the importance of the male gaze for determining the worth of women in the west. I have attempted to demonstrate with this project how a woman's worth and ability to achieve individuality or self in our society is determined by her ability to conform to a set of restrictive regulations that make the woman worthy of that complete status. Furthermore, the standard of what constitutes beauty in western society privileges whiteness as well as a very specific set of other phenotypic expressions. This western standard of beauty was clearly promoted by the organization Beauty Without Borders. It was by conforming to western standards of makeup and hair style that the women of Afghanistan could be liberated. There is of course the assumption here that western standards of beauty are liberating. However, those standards of beauty are fundamentally structured by the male gaze. Western beauty is about making women appealing to men. It is a western woman's ability to attract the male gaze that makes her worthy. Those women who do not conform to these standard, are of less worth. I also think that the importance of the male gaze in determining the value of women raises problems with the argument made by Young that the logic of masculinist protection is fundamentally different than the sexual domination of women by men. While the logic of masculine protection may seem chivalrous and as motivated by a noble desire to protect women and children, what is really being protected is the protecting man's exclusive sexual and reproductive rights to that woman.

Furthermore, the protective male is also protecting his labour by ensuring that he does not 
inadvertently expend his efforts raising the children of another male. While sexual domination and the logic of masculine protection may be discursively distinct, I think that the distinction is fundamentally at the conceptual level and that the motivations of each remain linked.

In the shadow of this security state and a War on Terrorism justified as a war to liberate women, a campaign of terrorism against women has developed: GamerGate. A group of women involved in the video gaming industry in various ways, game developers, gaming journalist, and even cultural critics were subjected to aggressive and organized campaigns of harassment (see (Sarkeesian, 2015), (Parkin, 2014), (Lewis, 2015) and (Wu, 2015)). These women were viewed to have overstepped their bounds by intruding on the male space of video games. These women faced constant harassment in all online environments, their personal data was distributed online and they received rape and death threats. While our leaders and military were apparently engaged in a war to liberate the women of Afghanistan, the women of the west were being systematically harassed in an effort to exclude them from the cultural space of gaming. I see the organized terrorist campaign of Gamergate not only as attempting to exclude women from the space of gaming but more generally an effort to push women out of the burgeoning public sphere that is the internet. Milo Yiannopoulos is a disgraced journalist for the far right website Breitbart. Milo rose to fame due to his aggressive participation in the terrorist campaign of Gamergate (Lees, 2016). However, Milo's 'journalism' for Breitbart clearly demonstrates how Gamergate was a broader campaign to force women from the public sphere of the internet. Breitbart published an article written by Milo entitled "The Solution To Online 'Harassment' Is Simple: Women Should Log Off" 
(Yiannopoulos, 2016). According to Milo's logic, if women do not want to deal with death and rape threats or if they really want to protect their personal data then the solution is for them to leave the public space of the internet. For this reason I see the events of Gamergate as a fundamentally important battle that women need to fight. The fight for representation and space in online cultures is a fight for access to the public sphere.

As I explained this project has very much functioned as a project of self understanding and self creation. However, the self that I have been trying to construct my academic self - has been repeatedly disrupted and challenged by the very bureaucratic forces of the institution with which I am trying to form the necessary matrix of relations. Because of the various crises that I faced over the course of this project, my progress was slow and took significantly longer than a typical Master's level project. For this reason, I had a very unstable and ambiguous status as a graduate student. I had to repeatedly request and justify the additional time that I needed to complete this project. Unfortunately, each of these requests facilitated a minor crisis in my sense of self. Requesting additional time made me feel like a failure, a fuck up and made me question my ability to actually achieve my goal. Things don't always go as we expect them to and often bureaucracies are ill equipped to deal with the realities of life.

Finally, to return to the popular cultural product that is at the heart of this project, what is the source of my attraction to this particular series and in particular the characters Lori and Andrea? This is a question that I had not explicitly considered until now. A suggestion from one of my professors was that perhaps they each represent an archetype of female character in horror fiction "the subordinate woman who submits to patriarchy and the agential woman who refuses to fall into line" (Gerlach, 2017). I was asked if I 
saw myself as falling somewhere in between these two archetypes? While I think this is a compelling idea I think it falls somewhat short of how I see my connection to and understanding of the series. In my view it is impossible for a woman in either the fantasy world of The Walking Dead or the real world of my life to adequately live up to all of the requirements of a good woman. All women, both the fantasy characters and the women of the real world, must walk a precarious line between being individuals making their own decisions and choices and being good women who are seen as worthy of health, happiness and liberty. In the ordinary apocalypse faced by women who fail to live up to the standards of a good woman worthy of happiness and life, the apocalypse does not come from a breakdown of civilization. The apocalypse comes from the destruction of or failure to become the very limited and restricted self available to women. A woman's ability to achieve a complete self or identity is directly related to her ability to live up to the restrictive standards and options available to her. In the ordinary apocalypse, the zombie is not the monster that causes the apocalypse. Rather the zombie is the ultimate fate of women. When a woman fails to be a good woman there is a break down in her connection to civilization; the apocalypse occurs for the zombie woman because the culture actively denies that the woman's life has value. 


\section{BIBLIOGRAPHY}

Ahmed, S. (2004). The cultural politics of emotion.New York: Routledge.

Alexander, J. (2010). The celebrity-icon. Cultural Studies, 4(3), 323-336.

Appiah, K. A. (2009). Racial idenity and racial identification. In L. Black, \& J. Solomos (Eds.), Theories of race and racism: Areader . New York: Routledge.

Bishop, K. (2010). The idle proletariat. The Journal of Popuar Culture, 42(2).

Butler, J. (1990). The force of fantasy: Feminism Mappelthorp and discursive excess. In S. Salih (Ed.), A Judith Butbr reader (2004). Malden, MA: Blackwell Publishing.

Butler, J. (1999). Gender Trouble: Feminism and thesubversion of Identity. New York: Routledge.

Butler, J. (2004). The lesbian phallus and the mophological imaginary. In S. Salih (Ed.), The Judith Butkr Reader (pp. 138-179). Malden, MA.

Butler, J. (2009). Frames of War: When is life grevable. New York: Verso.

Butler, J. (2015). Senses of the subject. New York: Fordham University Press.

Charmaz, K. (2006). Constructing Groundel Theory: A practical guide through qualitative analysis. . Washington, D.C.: Sage Publications Ltd.

CheesyBirdMess. (2015, March 20). Olivia. Retrieved April 7, 2017, from thewalkingdeadforums.com: http://www.walkingdeadforums.com/forum/threads/olivia.232142/

Creed, B. (1993). The monstrous-feminine: Film, Feminism, psychoanalysisi. New York: Routledge.

Cronin, A. M. (2000). Consumerism and 'compulsory individuality': women will and potential. In S. Ahmed, J. Kirby, C. Lury, \& M. M. Skeggs (Eds.), 
Transformations: Thiking through feminism (pp. 273-287). New York:

Routledge.

Dendle, P. (2007). The Zombie as Barometer of Cultural Anxiety. In N. Scott (Ed.),

Monsters and he Monstrous: Myths and Metaphors of Enduring Eil (pp. 45-57).

Amsterdam: Rodop.

Denzin, N. (2001). The reflexive interview and a performative social science. Qualitative Research, 1(1), 23-46.

Ellis, C. (2004). The ethnographic I: A methdobgical novel aboutautoethmgraphy Wallnut Creek, CA: Altamira Press.

Ellis, C., Adams, T. E., \& Bochner, A. (2011). Autoethnography: An Overview. Forum: Qualitative Social Research, 12(1). Retrieved April 7, 2017, from http://www.qualitative-research.net/index.php/fqs/article/view/1589/3095

England, M. (2006). Breached Bodies and Home Invasions: Horific Representations of the Feminised body and Home. Gender, Place \& Culture: A Journal of Feminist Geography, 13(4).

Fibber. (2012, March 4). Who do you side with? Andra or Lori? Retrieved April 7, 2017, from thewalkingdeadforums.com: 
http://www.walkingdeadforums.com/forum/threads/who-do-you-side-withandrea-or-lori.13472/\#post-1118272

Flyvbjerg, B. (2011). Making social science matter: Why social inquiry fails and how it can succeed again. . Oxford: Cambridge University Press.

Foucault, M. (1978). The history of sexuality: Volume1 an introduction. (R. Hurley, Trans.) New York: Vintage Books.

Geertz, C. (1973). The Interprdation of Cultures: Selected Essays. New York: Basic Books.

Gerlach, N. (2017, March 26). Personal Correspondence.

Hawkesworth, M. (2006). Feminist inquiry: From poltical conviction to methdobgical innovation.Rutgers University Press.

Hibberd, J. (2016, October 25). WalkingDead premier ratings just beat everything. Retrieved April 7, 2017, from Entertainment Weekly: http://ew.com/article/2016/10/25/walking-dead-season-7-premiere-ratings/

Hine, C. (2011). Towards ethnography of television on the internet: A mobile strategy for exploring mundane interpretive activities. Media Culture \& Society, 33(4).

Jensen, K. B. (1991). Reception Analysis: Masscommunication as the social production of Meaning. In K. B. Jensen, \& N. W. Jankowski (Eds.), A Handbookof 
qualitative methdobgies for mass communication research (p. 135). New York: Routledge.

Jessica's Trust. (n.d.). Jessica's TrustRaising Awareness of Childbed Fever. Retrieved April 7, 2017, from http://www.jessicastrust.org.uk/

Jones, S. (2013). Gender Monstrosity: Deadgirl and the sexual politics of zombie-rape. Feminist Media Studies, 13(3), 525-539.

Kirkland, A. (2011). The Environmental Account of Obesity: A Case for Feminist Skepticism. Signs, 36(2).

Kirkman, D. A. (Producer), \& Kirkman, R. (Director). (2010-Present). The WalkingDead [Motion Picture].

Lauro, S. J., \& Embry, K. (2008). A zombie manifesto: The nonhuman condition in the era of advanced capitalism. Boundary2, 35(1), 85-108.

Lees, M. (2016, December 1). What Gamergate should havetaughtus aboutthe altright'. Retrieved April 7, 2017, from the Guardian: https://www.theguardian.com/technology/2016/dec/01/gamergate-alt-right-hatetrump

Lewis, H. (2015). Gamergate: a brief history of a computerage war. Retrieved April 7, 2017, from The Guardian: 
http://www.theguardian.com/technology/2015/jan/11/gamergate-a-brief-historyof-a-computer-age-war

Marshal1. (2009). Oxford Dictionary of Sociology. Oxford: Oxford University Press.

Memmi, A. (2009). Racism and difference. In L. Black, \& J. Solomos (Eds.), Theories of Race and Radism: A reader (2 ed.). New York: Routledge.

Nguyen, M. T. (2011). The biopower of beauty: humanitarian imperialism and global feminism in an age of terror. Signs: Journalof Women in Culture and Society, 36(2), 359-383.

Olivia (2015, March 20). Retrieved April 7, 2017, from thewalkingdeadforums.com: http://www.walkingdeadforums.com/forum/threads/olivia.232142/

Parkin, S. (2014, September 9). Zoe Quinns depression Quest. Retrieved April 2017, from The New Yorker: http://www.newyorker.com/tech/elements/zoe-quinnsdepression-quest

Paterson, N. (2008). Cannibalizing Gender and Genre: A feminist re-vision of George Romero's Zombie Films. In S. McIntosh, \& M. Leverette (Eds.), ZombieCulture: Autopsès ofthe living ded. Toronto: Scarecrow Press.

Perry, B., \& Olsson, P. (2009). Cyberhate: the globalization of hate. Information\& Communications Technology Law 18(2), 185-199.

Pham, M. T. (2011). The right to fasion in the age of terrorism. Signs: Joumal of women in culture and society, 36(2), 386-410.

Puri, A. (2006). The web of insights: The art and practive of webnography. International Journal of Marlet Research, 49(3). 
Rabin, R. C. (2014, May 14). Labs are told to start including a neglected variable:

Females. Retrieved April 7, 2017, from The New York Times:

http://www.nytimes.com/2014/05/15/health/nih-tells-researchers-to-end-sex-biasin-early-studies.html?hp\&_r=0

Reddit. (n.d.). r/thewalkingdead. Retrieved April 7, 2017, from

https://www.reddit.com/r/thewalkingdead/

Richardson, L. (2004). Writing: A Method of Inquiry. In S. N. Hesse-Biber (Ed.), Approades to Qualitative Research: A reader on Theory and Practice. New York: Oxford University Press.

Roulston, K., DeMarris, K., \& Lewis, J. B. (2003). Learning to interview in the social sciences. Quaslitative Inquiry, 9, 643-668.

Sarkeesian, A. (2015, December 10). Harassment through impersonation: The creation of a cyber mob.Retrieved April 7, 2017, from Feminist Frequency: Conversations with pop culture: http://feministfrequency.com/2015/12/10/harassment-throughimpersonation-the-creation-of-a-cyber-mob/

Saunders, R. A. (2012). Undead Spaced: Fear, Globalization, and the Popular Geopolitics of Zombiism. Geopolitics, 17, 80-104.

Shachar, A. (2009). The Birthright Lottery: Citizenship and GlobaInequality. Cambridge: Harvard University Press.

Slocum, D. (2011). 9/11 Film and Media Scholarship. Cinema Journal 51(1), 181-193.

Sweetsister, Zambi, TheILLness, ShaneFan946, Fuyuko, \& Butercup. (2012, March 4). Who Do You Side With? Andra or Lori? Retrieved April 7, 2012, from thewalkingdeadfourms.com: 
http://www.walkingdeadforums.com/forum/threads/who-do-you-side-withandrea-or-lori.13472/\#post-1118272

Syphon. (2012, February 27). What Shout Be Done with Randal?Retrieved April 7, 2017, from thewalkingdeadforums.com: http://www.walkingdeadforums.com/forum/threads/what-should-be-done-withrandal.12712/

Syphon. (2012, March 4). Who Do You Side With? Andra or Lori? Retrieved April 7, 2017, from thewalkingdeadforums.com:

[URL="http://www.walkingdeadforums.com/forum/threads/who-do-you-sidewith-andrea-or-lori.13472/\#post-1118252"]Who do you side with? Andrea or Lori?[/URL]

TGO. (2015, March 20). Olivia Retrieved April 7, 2017, from thewalkingdeadforums: http://www.walkingdeadforums.com/forum/threads/olivia.232142/

The Walking Dead Forums. (n.d.). Forums Retrieved April 7, 2017, from The Walking Dead Forums: http://www.walkingdeadforums.com/forum/

TheILLness. (2012, March 4). Who do you side with? Andra or Lori? Retrieved April 7, 2017, from thewalkingdeadforums.com: 
http://www.walkingdeadforums.com/forum/threads/who-do-you-side-withandrea-or-lori.13472/\#post-1118272

Turner, G. (2004). Understanding cdebrity. London: Sage Publications.

WalkingBuckeye. (2015, March 20). Olivia. Retrieved April 7, 2017, from thewalkingdeadforums.com: http://www.walkingdeadforums.com/forum/threads/olivia.232142/

What Shout Be Done with Randal?(2012, February 27). Retrieved April 7, 2017, from thewalkingdeadforums.com: http://www.walkingdeadforums.com/forum/threads/what-should-be-done-withrandal.12712/

Who Do You Side with? Andre or Lori? (2012, March 4). Retrieved April 7, 2017, from thewalkingdeadforums.com: http://www.walkingdeadforums.com/forum/threads/who-do-you-side-withandrea-or-lori.13472/\#post-1118392

Who Would You Have Sided wih. (2012, March 5). Retrieved April 7, 2017, from thewalkingdeadforums.com: http://www.walkingdeadforums.com/forum/threads/who-would-you-have-sidedwith.13702/

Wiliams, L. (1984). When the woman looks. In M. Doane, P. Mellencamp, \& L. Williams. (Eds.), Re-vision: Essays in feminist film criticism. Los Angeles: University Publications of America.

Wu, B. (2015, August 21). The Guardian Retrieved April 7, 2017, from A moment that changed me - Gamergate: 
http://www.theguardian.com/commentisfree/2015/aug/21/gamergate-sexismgames-industry-women-trolls

Yiannopoulos, M. (2016, July 5). The Solution To Online 'Harassment' s Simple:

Women Should Iog Off. Retrieved April 7, 2017, from Breitbart:

http://www.breitbart.com/milo/2016/07/05/solution-online-harassment-simplewomen-log-off/

Young, I. M. (2003). The logic of masculinist protection: Reflection on the current security state. Signs, 29(1), 1-25.

Zambi. (2012, March 4). Who do you side with? Andra or Lori? Retrieved April 7, 2017, from thewalkingdeadforums.com:

http://www.walkingdeadforums.com/forum/threads/who-do-you-side-withandrea-or-lori.13472/\#post-1118272 